\title{
Fifty years of oxacalix[3]arenes: A review
}

\author{
Kevin Cottet $^{1,2}$, Paula M. Marcos ${ }^{3}$ and Peter J. Cragg ${ }^{* 1}$
}

\author{
Review \\ Address: \\ ${ }^{1}$ School of Pharmacy and Biomolecular Sciences, Huxley Building, \\ University of Brighton, Brighton BN2 4GJ, UK, ${ }^{2}$ UFR de Chimie, \\ Université Joseph Fourier Grenoble 1, 301 rue de la Chimie, BP53 - \\ 38041 Grenoble Cedex 9, France and ${ }^{3}$ Centro de Ciências \\ Moleculares e Materiais, FCUL, Edifício C8, 1749-016 Lisboa, \\ Portugal and Faculdade de Farmácia da Universidade de Lisboa, Av. \\ Prof. Gama Pinto, 1649-003 Lisboa, Portugal \\ Email: \\ Peter J. Cragg* - P.J.Cragg@brighton.ac.uk \\ * Corresponding author \\ Keywords: \\ calixarenes; host-guest chemistry; macrocycles; oxacalixarenes
}

Beilstein J. Org. Chem. 2012, 8, 201-226.

doi:10.3762/bjoc. 8.22

Received: 15 October 2011

Accepted: 11 January 2012

Published: 07 February 2012

This article is part of the Thematic Series "Supramolecular chemistry II".

Guest Editor: C. A. Schalley

(C) 2012 Cottet et al; licensee Beilstein-Institut. License and terms: see end of document.

\begin{abstract}
Hexahomotrioxacalix[3]arenes, commonly called oxacalix[3]arenes, were first reported in 1962. Since then, their chemistry has been expanded to include numerous derivatives and complexes. This review describes the syntheses of the parent compounds, their derivatives, and their complexation behaviour towards cations. Extraction data are presented, as are crystal structures of the macrocycles and their complexes with guest species. Applications in fields as diverse as ion selective electrode modifiers, fluorescence sensors, fullerene separations and biomimetic chemistry are described.
\end{abstract}

\section{Introduction}

Calixarenes, macrocycles which are widely used in supramolecular chemistry, are 2,6-metacyclophanes with a methylene bridge between their phenolic groups, as shown in Figure 1 [1-3]. In 1994, the term "homocalixarene" was coined by Brodesser and Vögtle to describe analogues of calixarenes with two or more methylene groups between the aromatic moieties [4]. When one or more $\mathrm{CH}_{2}$ bridges are replaced by $\mathrm{CH}_{2} \mathrm{OCH}_{2}$ groups the macrocycles are known as homooxacalixarenes, or simply oxacalixarenes. The presence of the heteroatom is reflected in the name of the compound, for example, $p$-tertbutylcalix[4]arene (1) with a $\mathrm{CH}_{2} \mathrm{OCH}_{2}$ group instead of a $\mathrm{CH}_{2}$ bridge is $p$-tert-butyldihomooxacalix[4]arene (2) [5]. "Dihomo" implies two additional atoms in the bridge and "oxa" that one of them is oxygen. The remainder of the calixarene nomenclature denotes any substituents attached to the phenolic oxygens, known as the "lower rim", and substituents found in the paraposition of the phenols, also known as the "upper rim" (Figure 2). For the purposes of this review the term "oxacalix $[n]$ arene" will be used as a generalization for this class of compounds.

Although some aspects of homooxacalixarene chemistry have been reviewed [4,6-8], notably by Shokova and Kovalev in $2004[9,10]$, it is timely for the $50^{\text {th }}$ anniversary of Hultzsch's 

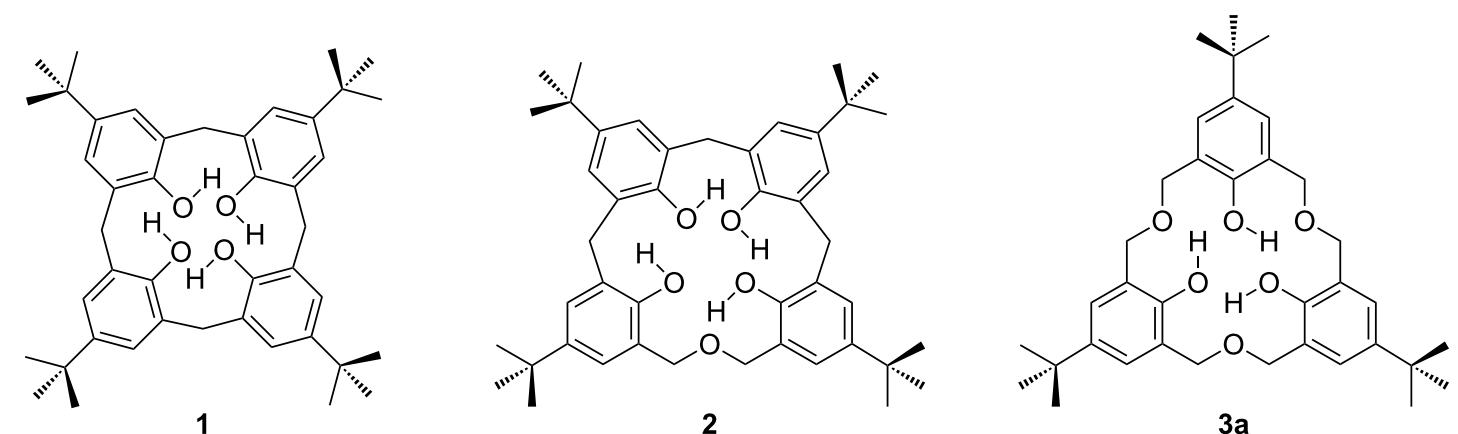

Figure 1: Calixarenes and expanded calixarenes: p-tert-Butylcalix[4]arene (1), p-tert-butyldihomooxacalix[4]arene (2), p-tert-butylhexahomotrioxacalix[3]arene (3a).

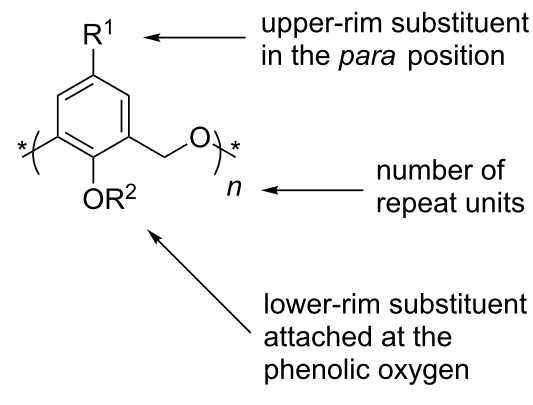

Figure 2: Conventional nomenclature for oxacalix[n]arenes.

discovery of $p$-tert-butylhexahomotrioxacalix[3]arene (3a) [11] to reflect on the history of these compounds and assess recent advances in the field. Many other expanded calix $[n]$ arenes are now known, including the methyl ethers of dihomooxa-, tetrahomodioxa-, hexahomotrioxa- and octahomotetraoxacalix[4]arenes, which have been described in detail by Masci [12]. Despite these advances, the oxacalix[3]arenes have remained the main focus of attention for researchers and are the subject of this review.

\section{Review}

\section{Synthesis of parent oxacalix[3]arenes 1.1 Thermal dehydration}

The first oxacalix $[n]$ arenes to be reported were the hexahomotrioxacalix[3]arenes, and these remain the most-studied members of the class. $p$-tert-Butylhexahomotrioxacalix[3]arene (3a), initially reported by Hultzsch in 1962, was isolated in less than $1 \%$ yield by heating 2,6-bis(hydroxymethyl)-4-tert-butylphenol [11]. Elemental analysis gave an empirical formula of $\mathrm{C}_{12} \mathrm{H}_{16} \mathrm{O}_{2}$ and molecular weight determinations gave values corresponding to a trimer. Despite interest in novel phenol-formaldehyde polymers and macrocycles and characterization of 3a in 1979 [13], it took a further 20 years for a reproducible synthesis to be published. In 1983, Gutsche reported that the thermally induced dehydration of 2,6-bis(hydroxymethyl)phenols in xylene under reflux gave rise to the formation of homooxacalixarenes, some of them in reasonable yields, as shown in Scheme 1 [14].

Although not discussed by Gutsche, both cyclotrimers and tetramers are usually formed by this method and, in 1991, Vicens and Zerr performed a thermal dehydration of 2,6-bis(hydroxy-

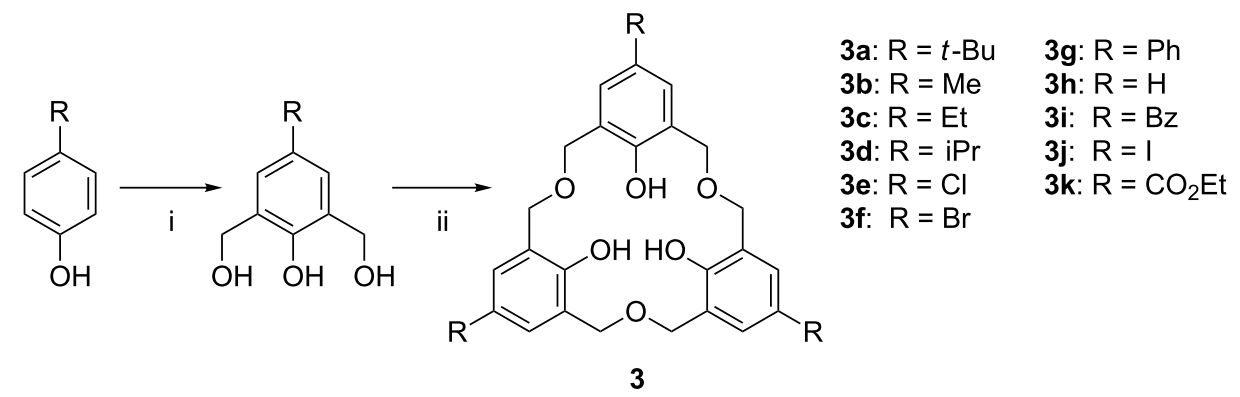

Scheme 1: Synthesis of oxacalix[3]arenes: (i) Formaldehyde (37\% aq), $\mathrm{NaOH}(\mathrm{aq}), 1,4$-dioxane; glacial acetic acid, acetone; (ii) refluxing o-xylene [14] or $\mathrm{Na}_{2} \mathrm{SO}_{4}, \mathrm{MsOH}$, in refluxing DME [15]. 
methyl)-4-tert-butylphenol in xylene under reflux allowing them to isolate $p$-tert-butyloctahomotetraoxacalix[4]arene (4a), illustrated in Figure 3, along with 3a [16].

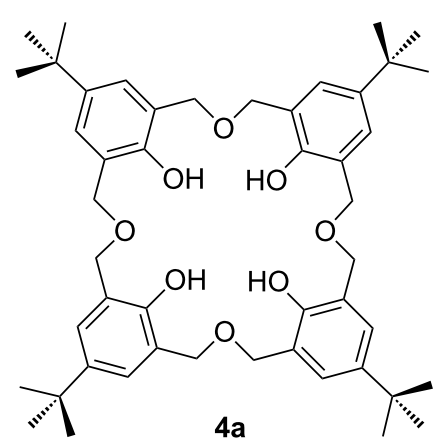

Figure 3: p-tert-Butyloctahomotetraoxacalix[4]arene (4a) [16].

To finally prove that the main product from thermal dehydration was indeed a trimer, Vicens reported the X-ray crystal structure of 3a in 1992 (Figure 4) demonstrating it to be exclusively in the bowl-shaped cone conformation [17].

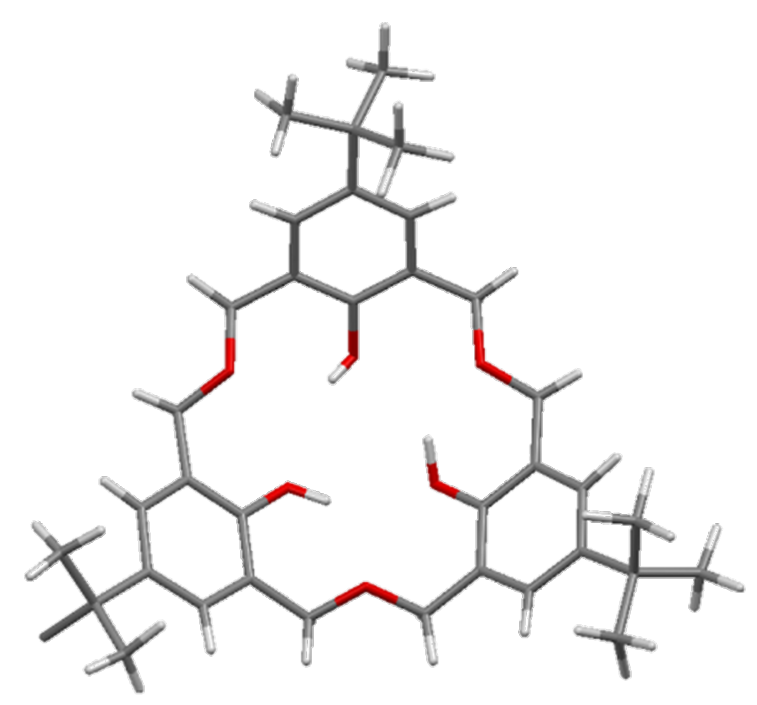

Figure 4: X-ray crystal structure of 3a showing phenolic hydrogen bonding (IUCr ID AS0508) [17].

In 1994, Hampton et al. used an alternative acid-catalyzed procedure to prepare 3a and developed a method that improved its purity through the formation of the $\mathrm{Na}^{+}$salt and its subsequent neutralization with acid [15]. The process separated 3a from the cyclic tetramer; the former precipitates as the sodium salt in dry methanol due to complementarity between the arrangement of phenolic groups and the preferred coordination environment of $\mathrm{Na}^{+}$. Removal of the tert-butyl groups through a conventional $\mathrm{AlCl}_{3}$ driven retro-Friedel-Crafts de-tert-butylation reaction, as seen in other calixarenes, is unsuccessful in the case of oxacalixarenes, therefore different para-substituents must be introduced through the starting phenol in order to obtain derivatives with different groups at the upper rim. A number of other para-substituted bis(hydroxymethyl)phenols were therefore also cyclized in the presence of methanesulfonic acid $(\mathrm{MsOH})$ or para-toluenesulfonic acid ( $\mathrm{TsOH}$ ) and $\mathrm{Na}_{2} \mathrm{SO}_{4}$. The corresponding oxacalixarenes were isolated in varying yields: $t$ - $\mathrm{Bu}$ (3a) 32\%; $\mathrm{Me} \mathrm{(3b)} \mathrm{21 \% ;} \mathrm{Et} \mathrm{(3c)}$ 21\%; iPr (3d) 30\%; Cl (3e) $12 \%$ [15].

Although conditions were not necessarily optimal, the principles of oxacalix[3] arene syntheses had been established. Monomers react to give the cyclic trimer, predominantly, when heated under reflux in high-boiling-point organic solvents along with an organic acid. Water formed in the dehydration process must be removed through reaction with anhydrous drying agents or be collected in a Dean-Stark trap. In Gutsche's report, and presumably in the work of Hultzsch too, the bis(hydroxymethyl)phenol monomer was isolated as the sodium salt and neutralized with acetic acid. Upon removal of solvent, traces of the acid presumably remained and were taken through to the cyclization step. Cragg noted that acid had to be present for the cyclization to occur, as carefully purified monomers formed calix[4]arenes or dihomooxacalix[4]arenes rather than oxacalix[3] arenes when subjected to standard synthetic methods [18]. To test this theory, the synthesis of 3a was attempted in $o$-xylene under reflux by using either the freshly prepared crude monomer or the recrystallized monomer. The formation of $\mathbf{3 a}$ was observed in the reaction of the unpurified monomer, but not under acid-free conditions. Moreover, in separate experiments $\mathrm{MsOH}, \mathrm{TsOH}$ or glacial acetic acid $(\mathrm{AcOH})$ were added to reactions involving the recrystallized monomer. $\mathrm{MsOH}$ or TsOH, having complementary threefold symmetry with the lower rim of oxacalix[3] arenes, were expected to increase the yields, but $\mathrm{AcOH}$ appeared to be just as effective. Notably, the addition of $\mathrm{TsOH}$ gave the oxacalix[3] arene as the sole product.

\subsection{Other synthetic methods}

Since the initial reports of oxacalix[3]arene syntheses, several procedures have been developed to improve both the reaction conditions and the range of derivatives that can be prepared. The initial strategy to make oxacalix[3] arenes was a single step condensation, which can only lead to $C_{3}$-symmetric compounds bearing the same para-substituted phenol; however, in host-guest chemistry an asymmetric macrocycle can provide a site for enantioselective molecular recognition. In the case of $p$-tert-butylcalix $[n]$ arenes the tert-butyl substituent can be removed, as mentioned previously, through a retroFriedel-Crafts acylation, and replaced by other groups, but the dibenzyl ether bridge in the oxacalixarenes is too fragile for this 
to be successful. In 1998, Fuji proposed a stepwise synthesis of asymmetric oxacalix[3]arenes based on linear precursors protected with a combination of isopropylidene and methoxymethyl groups [19]. As shown in Scheme 2, the phenolic position of a monomeric precursor is protected with methyl chloromethyl ether (MOMCl). A different monomer is then protected with 2,2-dimethoxypropane, in the presence of TsOH. This links one methylol group to the phenol, leaving the second open to bromination with $\mathrm{CBr}_{4}$ and $\mathrm{PPh}_{3}$. The linear trimer is formed between one methoxymethyl protected monomer and two benzyl bromide derivatives in DMF with $\mathrm{NaH}$ as the base. Intramolecular cyclization was achieved in $4 \mathrm{~h}$ at room temperature with $60 \% \mathrm{HClO}_{4}$ in $\mathrm{CHCl}_{3}$ under high-dilution conditions. Pretreatment of the solvent with water was found to be necessary to remove the ethanol stabilizer and to aid deprotection. Yields were up to 50\%, and, interestingly, there was no template effect from any alkali metals. An analogous strategy was developed by Georghiou in 2001 to prepare asymmetric oxacalix[3]naphthalene derivatives [20], and this is discussed in greater detail below.

In a later communication, Fuji reported the crystal structure of an unusual byproduct of the reaction, a heptahomotetraoxacalix[3] arene 5 with $t$-Bu, Et and $\mathrm{H}$ upper-rim substituents (Figure 5) [21].

In 2001, Komatsu proposed a different way to access compounds in which two, or all three, units are identical [22]. The method was based on the reductive coupling of silylated derivatives of 2,6-hydroxymethylphenols, in which $\mathrm{R}$ is $t$-Bu, Me, benzyl (Bz), phenyl $(\mathrm{Ph})$, or a halide, as shown in Scheme 3. The reaction takes place under conditions of high dilution at $-78{ }^{\circ} \mathrm{C}$ to favour intramolecular cyclization over polymeriza-

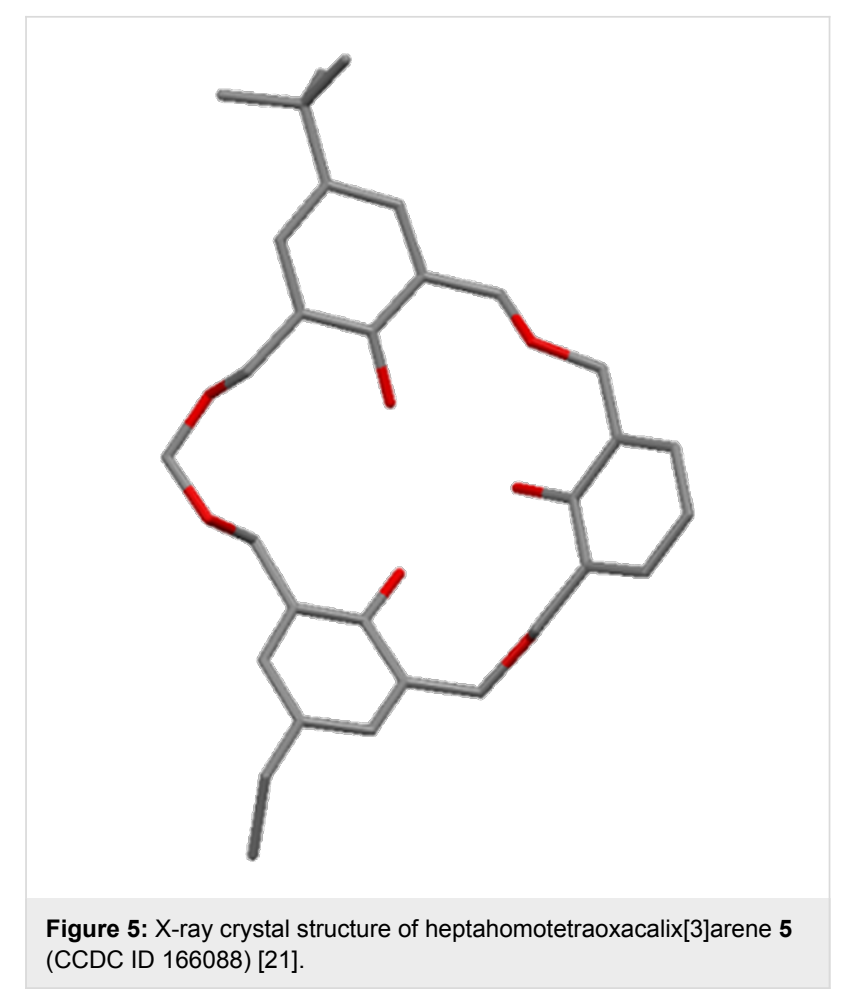

tion. Coupling reactions are successful, whether the groups in the para-position are the same or different, and this method also gives access to oxacalix[4] arenes in modest yields up to $42 \%$ for the $p$-tert-butyl derivative.

\subsection{Oxacalix[3]naphthalenes}

The oxacalix[3]naphthalenes, e.g., $6 \mathbf{a}$ and $\mathbf{6 b}$ reported by Georghiou, have extended aromatic groups with $\mathrm{H}$ or $t$-Bu groups in the 6-position and can be considered as close relatives of the oxacalix[3]arenes [20]. The synthesis, shown in<smiles>[R]c1cc(CO)c(O)c(COCc2cc([R])cc(COCc3cc([R])cc(COCc4cc([R])cc(COCc5cc([R])cc(COCc6cc([R])cc(COCc7cc([R])cc(CO)c7O)c6OCOC)c5OCOC)c4OCC(C)C)c3OCOC)c2O)c1</smiles>

Scheme 2: Stepwise synthesis of asymmetric oxacalix[3]arenes: (i) MOMCl, Adogen ${ }^{\circledR} 464$; (ii) 2,2-dimethoxypropane, $p$ - $\mathrm{TsOH}$; (iii) $\mathrm{CBr} 4$, $\mathrm{PPh}_{3}$, $\mathrm{CH}_{2} \mathrm{Cl}_{2}$; (iv) $\mathrm{NaH}$, DMF; (v) $\mathrm{HClO}_{4}$ (aq), wet $\mathrm{CHCl}_{3}[19]$. 


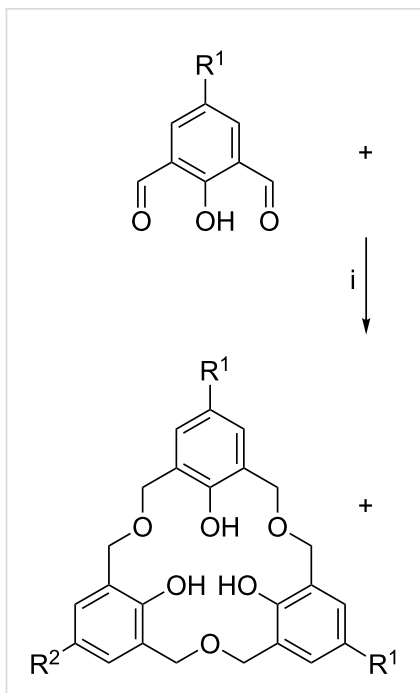

3

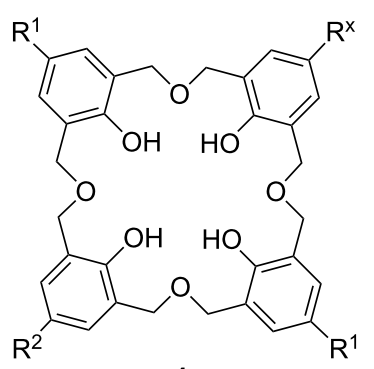

4

Scheme 3: Oxacalix[3]arene synthesis by reductive coupling: (i) $\mathrm{Me}_{3} \mathrm{SiOTf}, \mathrm{Et}_{3} \mathrm{SiH}, \mathrm{CH}_{2} \mathrm{Cl}_{2} ; \mathrm{R}^{1}, \mathrm{R}^{2}=\mathrm{I}, \mathrm{Br}$, benzyl, $n$-octyl (x = 1 or 2 ) [22].

Scheme 4, is analogous to Fuji's method for oxacalix[3]arenes [19]. As noted below, this extended aromatic surface is oriented perfectly for $\mathrm{C}_{60}$ inclusion [23].

\section{Conformational properties}

Oxacalix[3] arenes have received significant attention as receptors, mainly due to their structural features: A cavity formed by a 18-membered ring, only two basic conformations (cone and partial-cone), and a $C_{3}$-symmetry [24]. This last feature can provide a suitable binding site for species that require trigonal-planar, tetrahedral or octahedral coordination environments. The flexibility of the macrocycles can allow them to establish ideal bond distances and angles to bind such species. In common with other calix $[n]$ arenes, oxacalix[3] arenes containing free $\mathrm{OH}$ groups are conformationally mobile, leading to cone and partial-cone conformers
(Figure 6). Without lower-rim substituents there is free rotation of each phenolic unit through the macrocyclic annulus; however, the presence of a hydrogen-bond motif in the cone conformer makes it the more stable form.

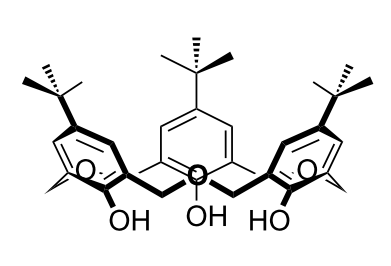

cone

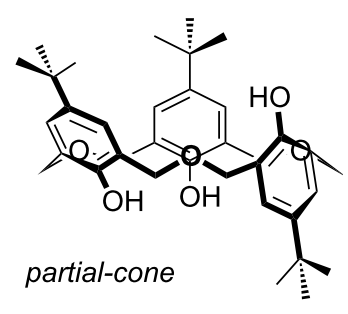

Figure 6: Conformers of $3 a$

In 1985, Gutsche investigated the conformational flexibility of parent calix $[n]$ arenes $(n=4-8)$ and oxacalixarenes by temperature-dependent ${ }^{1} \mathrm{H}$ NMR [5]. The through-the-annulus rotation barrier for oxacalix[3] arenes was calculated to be much lower than that for other calixarenes, either in non-coordinating or in polar solvents, such as $\mathrm{CDCl}_{3}$ or pyridine, respectively. The ${ }^{1} \mathrm{H}$ NMR spectrum of $\mathbf{3 a}$ in $\mathrm{CDCl}_{3} / \mathrm{CS}_{2}$ only showed a singlet for the $\mathrm{CH}_{2}$ resonance, even at $-90{ }^{\circ} \mathrm{C}$, and the $\Delta G^{\neq}$barrier for conformational inversion in $\mathrm{CDCl}_{3}$ was $<38 \mathrm{~kJ} \mathrm{~mol}^{-1}$, in contrast with $66 \mathrm{~kJ} \mathrm{~mol}^{-1}$ for the calix[4]arene analogue. To freeze the oxacalix[3] arene conformer, through-the-annulus rotation must be prevented. This can be achieved by the introduction of sufficiently large groups on the lower rim of the macrocycle. Upper-rim inversion is less likely to occur when, as in the case of $\mathbf{3 a}$, it is hindered by the tert-butyl group.

\section{Oxacalix[3]arene derivatives}

\subsection{Lower-rim derivatives}

Oxacalix[3]arene derivatization at the lower rim has been achieved through alkylation reactions with simple alkyl halides or with functionalized alkylating agents. Lower-rim derivatiza-<smiles></smiles><smiles>[R]c1ccc2cc(O)c(COCc3c(COCc4c(O)c(COCc5c(O)c(COCc6ccccc6)cc6cc([R])ccc56)cc5cc([R])ccc45)cc4cc([R])ccc4c3O)cc2c1</smiles> 


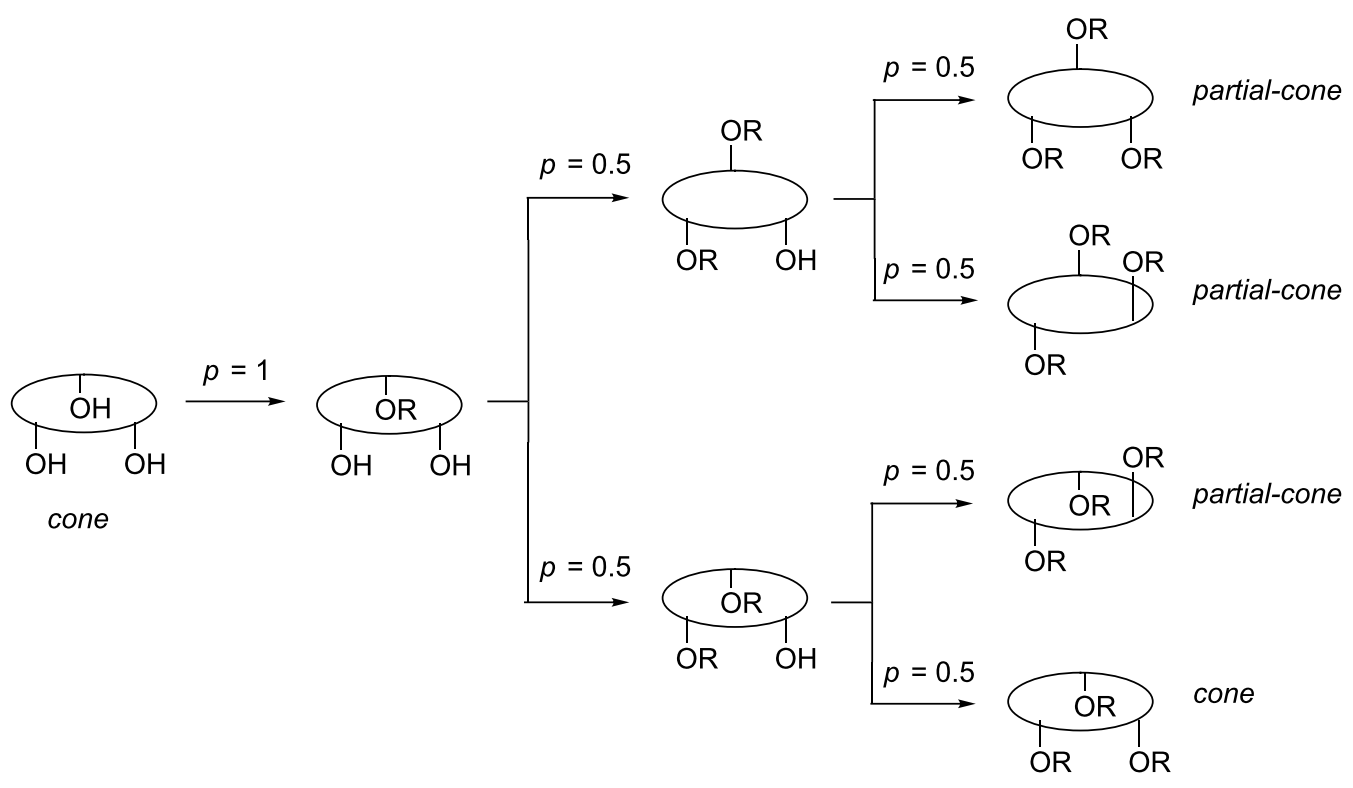

Scheme 5: Origin of the 25:75 cone:partial-cone statistical distribution of O-substituted oxacalix[3]arenes $(p=$ probability $)[25,26]$.

tion is relatively straightforward, but conformational control is harder to achieve. The main drawback of lower-rim substitution is that statistically only $25 \%$ of the product is formed in the cone conformation, as shown in Scheme $5[25,26]$.

3.1.1 Alkyl ethers: Classical $O$-alkylation of oxacalix[3]arenes was first achieved by Shinkai et al. in 1993 [24]. Treatment of 3a with the corresponding alkyl halides in DMF in the presence of $\mathrm{NaH}$ afforded $\mathrm{Me}(\mathbf{7}), \mathrm{Et}(\mathbf{8}), n-\operatorname{Pr}(\mathbf{9})$ and $n-\mathrm{Bu}(\mathbf{1 0})$ derivatives (Scheme 6). Under these conditions, 8 was obtained in the partial-cone conformation only. When the reaction was performed in the presence of $t$-BuOK a 1:4 mixture of cone and partial-cone was obtained and even with $\mathrm{Cs}_{2} \mathrm{CO}_{3}$ the cone conformer could be detected. It seems that $\mathrm{K}^{+}$and $\mathrm{Cs}^{+}$favourably interact with the three phenolic oxygen atoms placed on the same side, whereas $\mathrm{Na}^{+}$preferentially interacts with them across the ring.<smiles>CC(C)(C)c1cc(CO)c(O)c(C(C)(C)C)c1</smiles>

3a
$R=M e$

8: $R=E t$

9: $\mathrm{R}=n-\mathrm{Pr}$ 10: $\mathrm{R}=n-\mathrm{Bu}$ [24]
Introduction of heteroatoms, such as nitrogen, into the oxacalix[3] arene lower rims can also be achieved by $O$-alkylation. Pyridine is known to be a good ligand towards metals and is widely employed in transition-metal coordination chemistry; therefore, in an attempt to incorporate these binding sites into oxacalix[3]arenes, Yamato [27] and Cragg [26] independently reacted 3a with 2-(chloromethyl)pyridine, as shown in Scheme 7. The presence of $\mathrm{Cs}_{2} \mathrm{CO}_{3}$ leads to the formation of the partial-cone conformer, whereas $\mathrm{K}_{2} \mathrm{CO}_{3}$ and $\mathrm{NaH}$ increase the yield of the cone conformer of 11a to about $25 \%$. ${ }^{1} \mathrm{H}$ NMR analysis of the cone conformer indicates that the nitrogen atoms point away from the macrocyclic cavity [27].

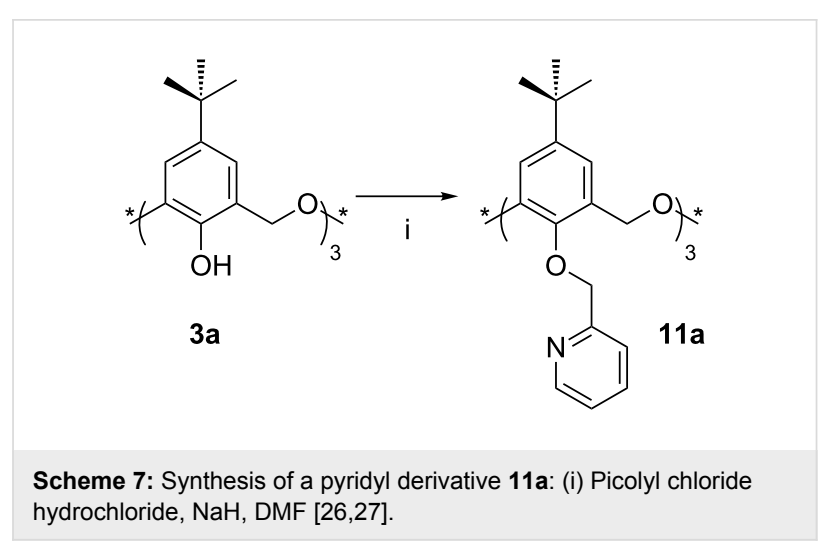

When 4-(chloromethyl)pyridine was used instead, $\mathrm{NaH}$ was ineffectual as a deprotonating agent. $\mathrm{Na}_{2} \mathrm{CO}_{3}$ yielded the disubstituted product only, $\mathrm{K}_{2} \mathrm{CO}_{3}$ gave both cone $(8 \%)$ and partial- 
cone $(68 \%)$ conformers, and the only isolated product with $\mathrm{Cs}_{2} \mathrm{CO}_{3}$ was the partial-cone conformer (75\%) [28].

The X-ray structure of the partial-cone conformer (Figure 7), reported by Cragg, shows one pyridyl group to be included within the macrocyclic cavity and the remaining two with their nitrogen atoms pointing away from it [26].

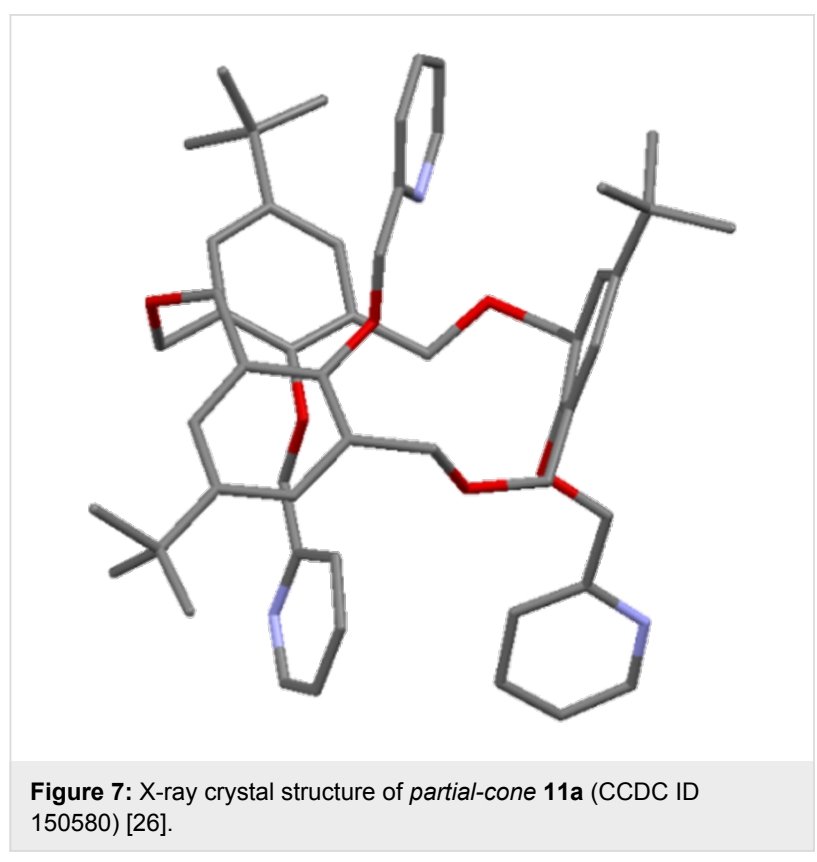

3.1.2 Functionalized alkyl ethers: Functionalized alkyl halides of the type $\mathrm{XCH}_{2} \mathrm{Y}$, where $\mathrm{X}$ is a leaving group and $\mathrm{Y}$ is a functional group, have also been used to introduce a variety of groups into the lower rim of oxacalix[3]arenes. Thus, derivatives containing carbonyl groups (ester, acid, amide and ketone) and heteroatoms, such as nitrogen and phosphorous, have been obtained.
In 1993, Shinkai et al. [29] reported the synthesis of the first ethyl ester derivative 12a. In the belief that the alkali-metal template effect would lead preferentially to the cone conformer with $\mathrm{NaH}$, the reaction of excess ethyl bromoacetate with $\mathbf{3 a}$ was carried out in acetone under reflux (Scheme 8). The partial-cone conformer of $\mathbf{1 2 a}$ was formed exclusively when weaker bases, $\mathrm{K}_{2} \mathrm{CO}_{3}$ or $\mathrm{Cs}_{2} \mathrm{CO}_{3}$, were used. $\mathrm{NaH}$ or $t$-BuOK in THF gave a mixture of products, but the yield of the cone conformer never exceeded $22 \%$. An experiment with the oxacalix[3]naphthalene analogue was performed in 2003 by Georghiou [30], which also gave the cone conformer in $25 \%$ yield.<smiles>CCOC(=O)COc1c(CO[Al])cc(C(C)(C)C)cc1C(C)(C)C</smiles>

Scheme 8: Lower-rim ethyl ester synthesis: (i) Ethyl bromoacetate, $\mathrm{NaH}, t$-BuOK or alkali metal carbonate, THF or acetone [29].

Cone-12a was used by Shinkai as the starting point from which to construct the chiral capped oxacalix[3] arene $\mathbf{1 3}$ as shown in Scheme 9 [31]. The parent compound was cleaved to form the tris(acid) 14a, which then reacted with $S$-phenylalanine methyl ester. Deprotection of the methyl ester followed by reduction with $\mathrm{LiBH}_{4}$ gave the chiral amide 15, which reacted with 1,3,5benzenetricarbonyl chloride to form the capped species $\mathbf{1 3}$. Compound 13 was shown to bind primary ammonium cations better than an uncapped ester analogue.<smiles>Cc1cc(C(C)(C)C)cc(COC(C)(C)C)c1O</smiles>

$3 a$<smiles>Cc1cc(C(C)(C)C)cc(COC(C)C)c1OCC(=O)O</smiles>

$14 a$<smiles>COC(=O)[C@H](Cc1ccccc1)NC(=O)COc1c(CO[Al])cc(C(C)(C)C)cc1C(C)(C)C</smiles>

15
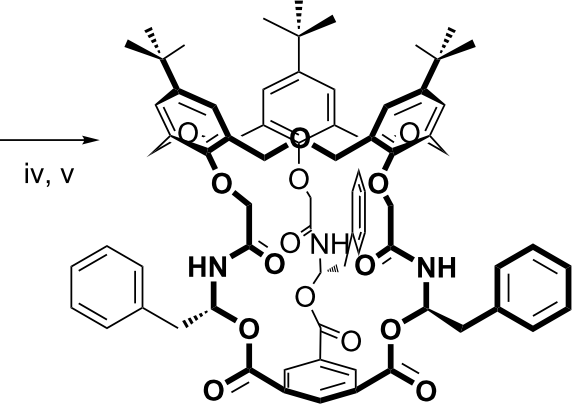

13

Scheme 9: Forming chiral receptor 13: (i) Ethyl bromoacetate, $\mathrm{NaH}$, THF; (ii) $\mathrm{NaOH}, \mathrm{H}_{2} \mathrm{O} / 1$,4-dioxane; (iii) S-PheOMe· $\mathrm{HCl}$, DCC, $\mathrm{HOBt}$, $\mathrm{NEt}{ }_{3}$, $\mathrm{CH}_{2} \mathrm{Cl}_{2}$; (iv) $\mathrm{LiBH}_{4}$, THF; (v) 1,3,5-benzenetricarbonyl chloride, pyridine, THF [31]. 
In 1995, Vicens reported the crystal structure of a partial-cone triethyl ester derivative of 4-phenyloxacalix[3]arene illustrated as 16 in Figure 8 [32]. Few synthetic details were given; however, it was reported that cyclization of bis(2,5-methylol)-4phenylphenol to give $\mathbf{3 g}$ was followed by reaction with ethylbromoacetate, but no mention of the yield or isolation of a cone conformer was made.

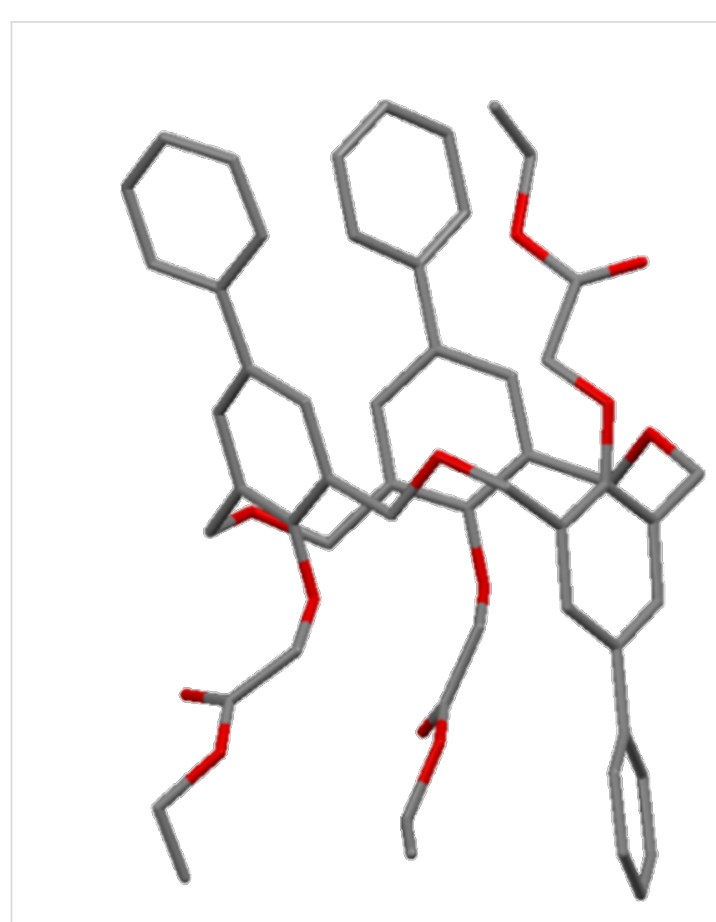

Figure 8: X-ray crystal structure of 16 (IUCr ID PA1110) [32].

The first amide derivative was reported by Shinkai in 1995 [25] through the reaction of 3a with $N, N$-diethylchloroacetamide (Scheme 10). Heating under reflux in THF, with $\mathrm{NaH}$ as base, gave cone amide $17 \mathbf{a}$ as the only isolated product in $23 \%$ yield. Using the same conditions, Cragg reported an improved yield of $44 \%$ through a slight modification of the previous procedure (recrystallization from $\mathrm{MeCN}$ instead of $\mathrm{MeOH}$ ) [26], and Yamato later reported a $90 \%$ yield [33]. This is in stark contrast to the maximum yield of $25 \%$ for the esterification reaction discussed above and points to a subtle, yet essential, difference between the interaction modes of the oxacalixarene, cation and alkylating agent. Despite much speculation, the reason for this is not yet understood. As with the esterification reaction, use of $\mathrm{K}_{2} \mathrm{CO}_{3}$ or $\mathrm{Cs}_{2} \mathrm{CO}_{3}$ in place of $\mathrm{NaH}$, and with acetone as the solvent, reverses the conformer preference with partial-cone$17 \mathrm{a}$ isolated in $45 \%$ yield with only a trace of the cone conformer. This suggests a template effect for both $\mathrm{K}^{+}$and $\mathrm{Cs}^{+}$ that occurs whether an amide or ester is formed, and a function for $\mathrm{Na}^{+}$beyond that of a mere template.

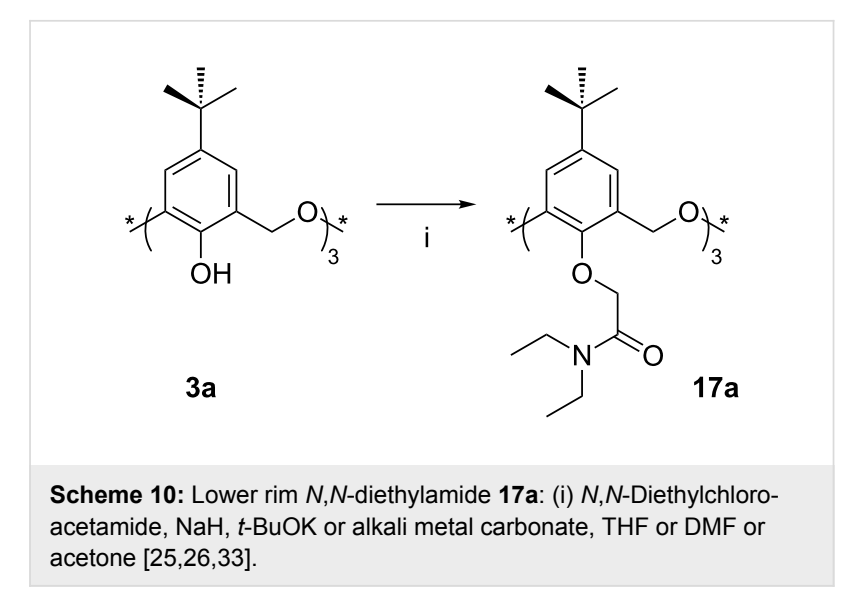

One consequence of this work is that the preferred route to $C_{3}$ symmetric cone derivatives is through tris(amide) derivative $\mathbf{1 7 a}$, which can readily be cleaved by hydrolysis employing sodium hydroxide in 1,4-dioxane/water to give cone-14a. In 2001 Yamato used cone-14a to form a $C_{3}$ symmetric hydrophobic receptor 18 in $13 \%$ yield through reaction with $1,3,5-$ tris(bromomethyl)benzene in the presence of $\mathrm{Na}_{2} \mathrm{CO}_{3}$ (Scheme 11) [33]. As the reaction failed to work when $\mathrm{K}_{2} \mathrm{CO}_{3}$ was used, the authors suggested that $\mathrm{Na}^{+}$may play a templating role in addition to that of a deprotonating agent.

The X-ray crystal structure of the product (Figure 9) shows that the carbonyl oxygen atoms point away from the cavity to create a large hydrophobic cavity. Extraction studies indicated a slight, and statistically insignificant, preference for $\mathrm{K}^{+}$over $\mathrm{Cs}^{+}$and $\mathrm{Ag}^{+}$, with a much lower affinity for $\mathrm{Na}^{+}$. The highest affinity was reserved for $n$ - $\mathrm{BuNH}_{3}{ }^{+}$.

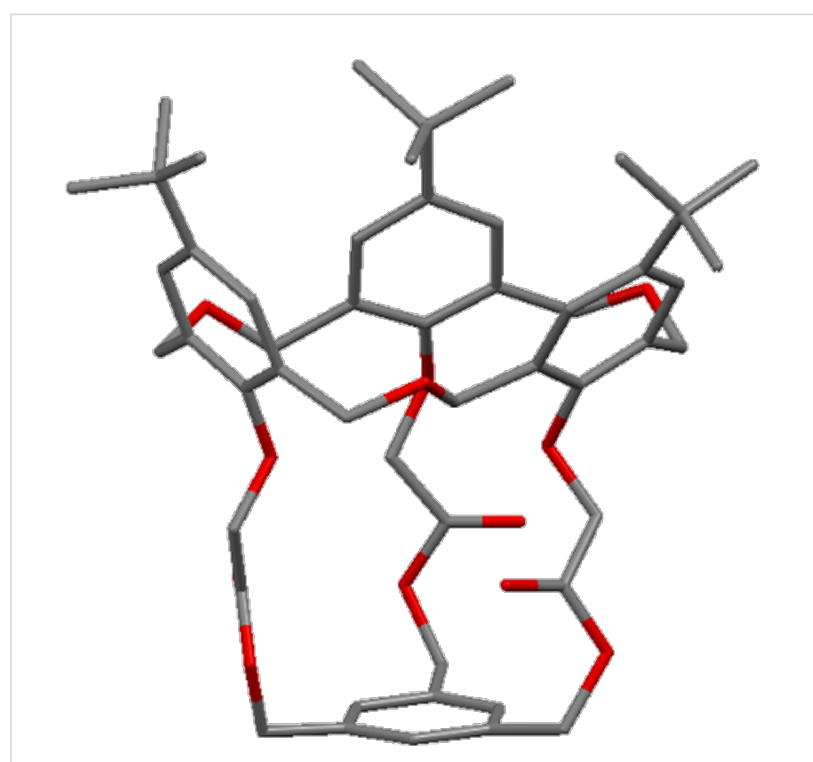

Figure 9: X-ray crystal structure of 18 (CCDC ID 142599) [33]. 


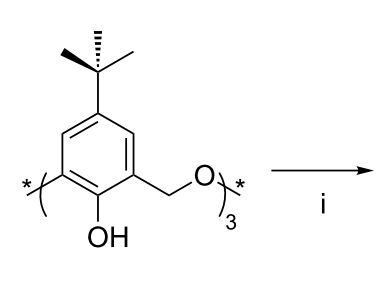

$3 a$

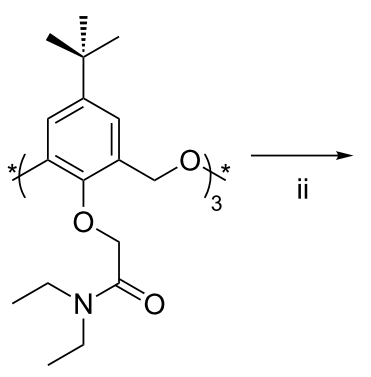

$17 \mathrm{a}$

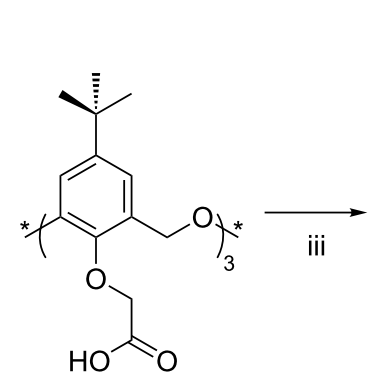

$14 a$

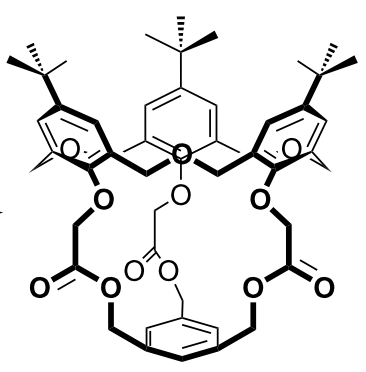

18

Scheme 11: Capping the lower rim: (i) N,N-Diethylchloroacetamide, $\mathrm{NaH}$, THF; (ii) $\mathrm{NaOH}, \mathrm{H}_{2} \mathrm{O} / 1,4$-dioxane; (iii) 1,3,5-tris(bromomethyl)benzene, $\mathrm{Na}_{2} \mathrm{CO}_{3}$, DMF [33].
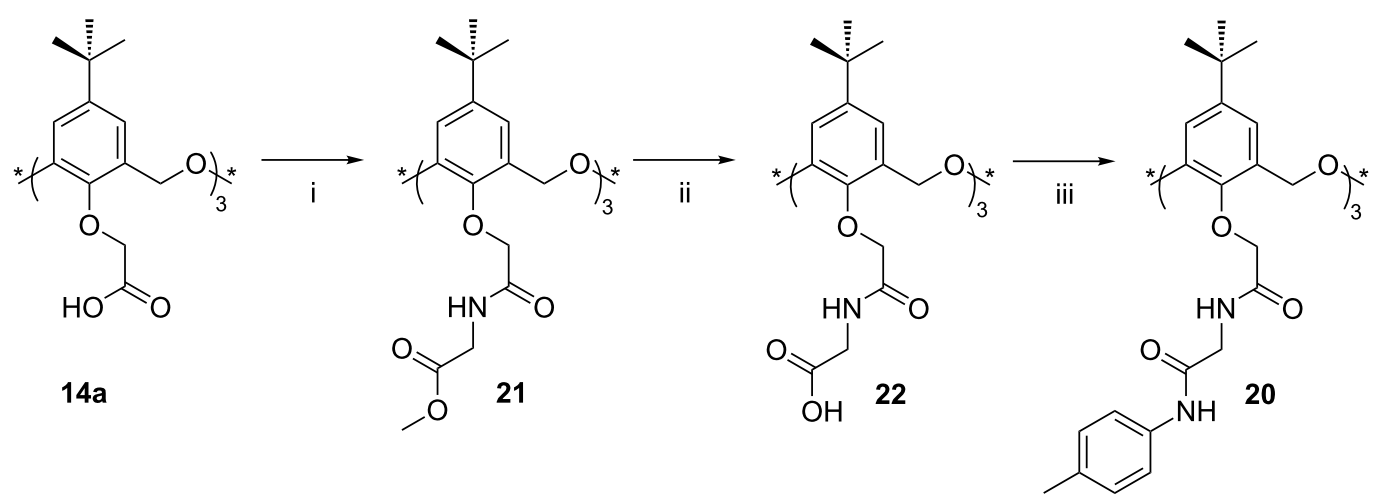

Scheme 12: Extending the lower rim: (i) Glycine methyl ester, $\mathrm{HOBt}$, dicyclohexycarbodiimide (DCC), $\mathrm{CH}_{2} \mathrm{Cl}_{2}$; (ii) $\mathrm{NaOH}, \mathrm{H}_{2} \mathrm{O} / 1$,4-dioxane; (iii) $p$-toluidine, $\mathrm{HOBt}, \mathrm{DCC}, \mathrm{CH}_{2} \mathrm{Cl}_{2}$ [37].

An analogue of 18, which showed little affinity for metal cations, was prepared with three 4-methylbenzyl substituents on the lower rim (19).

In 2001, Yamato reported an oxacalix[3] arene with pendant pyridines linked by amide bonds [34]. The intramolecular hydrogen bonds between neighbouring amide groups enforced a flattened-cone conformer for the macrocycle, which prevented binding to both metal cations and, to a large extent, alkyl ammonium cations. Extending the link between the macrocycle and aromatic termini did not disrupt the strong amide interactions, although binding was detected for $\mathrm{Ag}^{+}$, as the triflate, and for $n$ - $\mathrm{BuNH}_{3}{ }^{+}$, as the chloride salt [35]. Further work on this class of derivatives showed some anion selectivity in the presence of $n-\mathrm{BuNH}_{3}{ }^{+}$through intermolecular hydrogen bonding with amide hydrogens [36].

In 2006, the same group used a similar route in order to synthesize the extended, uncapped derivative $\mathbf{2 0}$ incorporating three (phenylcarbamoyl)methylcarbamate substituents (Scheme 12), to mimic the binding sites in a protein, complete with hydrophobic region [37]. These amides were designed to act as heteroditopic receptors, capable of binding anions and cations separately and simultaneously in a cooperative way, and were shown to bind $n-\mathrm{BuNH}_{3}{ }^{+}$halide salts in this manner.

$\mathrm{N}$-Hydroxypyrazinones are known to function as bidentate ligands for metals such as iron or gallium that require an octahedral geometry. Katoh coupled $N$-hydroxypyrazinone substituents to cone-14a in order to prepare 23 (Scheme 13). Binding $\mathrm{Ga}^{3+}$ with remote lower-rim groups induced the cooperative binding of alkyl ammonium cations by the macrocycle [38].

Recently, Marcos reported the synthesis of an oxacalix[3]arene ketone derivative (Scheme 14) [39]. Treatment of 3a with 1 -adamantyl bromomethyl ketone and $\mathrm{NaH}$ in THF under reflux afforded adamantyl ketone $\mathbf{2 4}$ in the cone conformation only.

3.1.3 Phosphorus derivatives: Complete phosphorylation of 3a was reported by Matt in 1999 and was achieved through reaction with $\mathrm{NaH}$ and $\mathrm{Ph}_{2} \mathrm{P}(\mathrm{O}) \mathrm{CH}_{2} \mathrm{OTs}$ in toluene at $90{ }^{\circ} \mathrm{C}$ for three days (Scheme 15) [40]. The reaction resulted in the forma- 


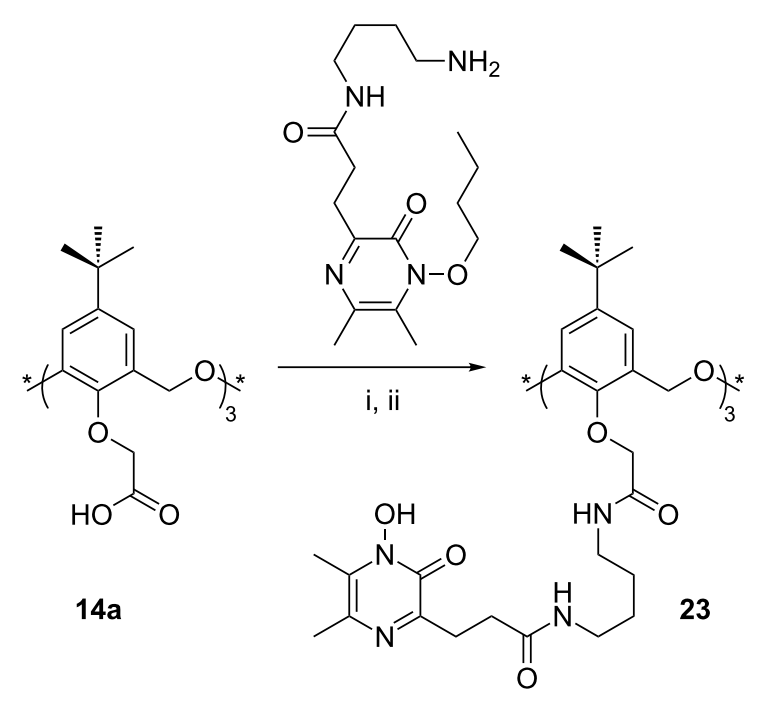

Scheme 13: Synthesis of $N$-hydroxypyrazinone derivative 23: (i) 1-[3(Dimethylamino)propyl]-3-ethylcarbodiimide hydrochloride, $\mathrm{HOBt}$, $\mathrm{Et}_{3} \mathrm{~N}$; (ii) $\mathrm{H}_{2}, 10 \% \mathrm{Pd}-\mathrm{C}, \mathrm{MeOH}$ [38].<smiles>Cc1cc(C(C)(C)C)cc(COC(C)C)c1O</smiles>

$3 \mathbf{a}$

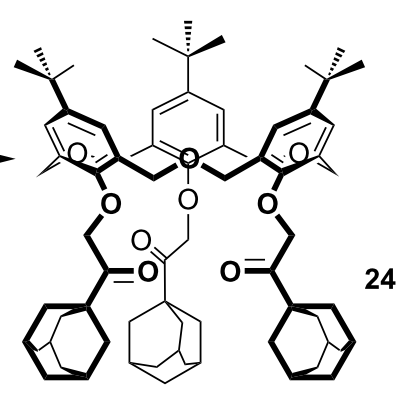

Scheme 14: Synthesis of 24: (i) 1-Adamantyl bromomethyl ketone, $\mathrm{NaH}, \mathrm{THF}[39]$.

tion of a 4:1 mixture of the cone and partial-cone diphenylphosphine oxide derivatives 25: The preference for the cone formation is highly atypical but may be due to the templating effect of $\mathrm{Na}^{+}$. Separation by column chromatography afforded the cone conformer in $72 \%$ yield although the partial-cone was never obtained in a pure form. Reduction by phenylsilane $\left(\mathrm{PhSiH}_{3}\right)$ gave the corresponding cone and partial-cone phosphines $\mathbf{2 6}$ quantitatively.

3.1.4 Silyl derivatives: In 1996, Hampton investigated the selectivity of silylation on oxacalix[3]arenes to determine the influence of the group in the para-position, the nature of the silylating agent and the reaction conditions [41]. Unsurprisingly, the formation of the partial-cone was favoured for all oxacalix[3] arenes, with small upper-rim substituents having the highest partial-cone:cone ratio (e.g., 100:1 for the $\mathrm{Cl}$ derivative) when bis(trimethylsilyl)trifluoroacetamide was used as the silylating reagent. When 1-(trimethylsilyl)imidazole was used, the ratios were 30 to $45: 1$ and were independent of the group in the para-position. A silylated p-tert-butyloxacalix[3]arene 27 was characterized by X-ray crystallography to confirm that it was in the partial-cone conformation as shown in Figure 10. These derivatives could serve as reaction intermediates, due to the ease with which the silicon-oxygen bond can be cleaved in the presence of fluoride, although this chemistry has yet to be explored.

3.1.5 Intramolecularly bridged derivatives: Linking two or more phenolic calixarene oxygen atoms together is a common method to improve selectivity and complex stability, and derivatives such as calixcrowns have been known for a considerable time [42]. Amido-di-O-bridged oxacalix[3]arenes were reported by Chen in 2005 through reaction of 3a with $N, N$ '-bis(chloroacetyl)- $\alpha, \omega$-alkylenediamines in refluxing acetone with $\mathrm{K}_{2} \mathrm{CO}_{3}$ as the base (Scheme 16) $[43,44]$. Those compounds linked by two (28) or three (29) methylene groups had a binding affinity for linear primary alkyl ammonium ions from $n-\mathrm{BuNH}_{3}{ }^{+}$to $n-\mathrm{HexNH}_{3}{ }^{+}$.

\subsection{Upper-rim derivatives}

Although the lower rim has many advantages as a binding site for guests, not least in the relative ease with which substituents

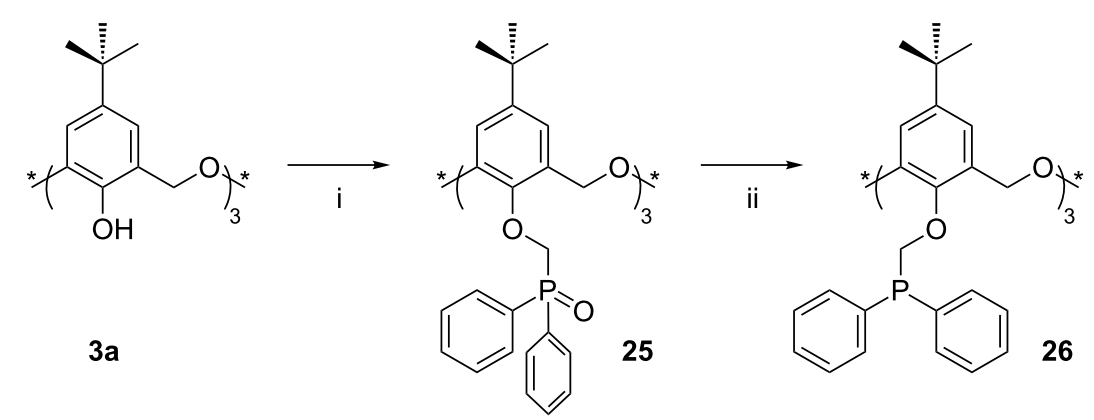




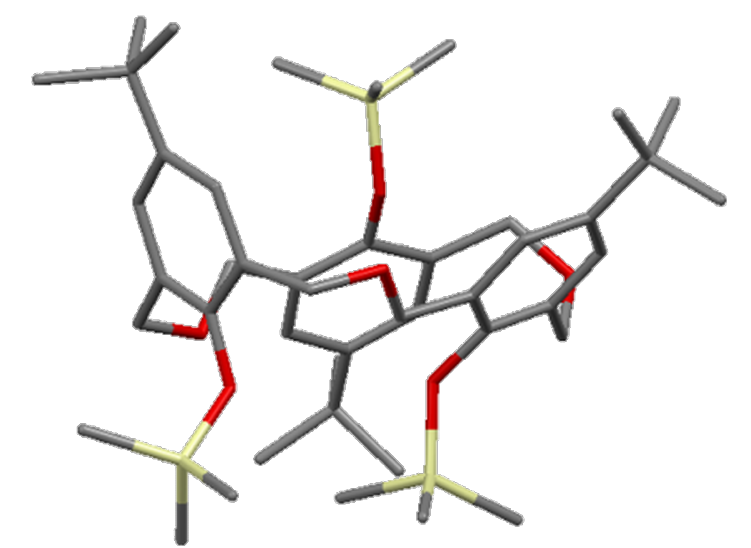

Figure 10: X-ray crystal structure of 27 in the partial-cone conformer (CCDC ID SUP 90399) [41].

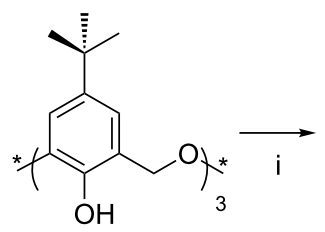

$3 \mathbf{a}$

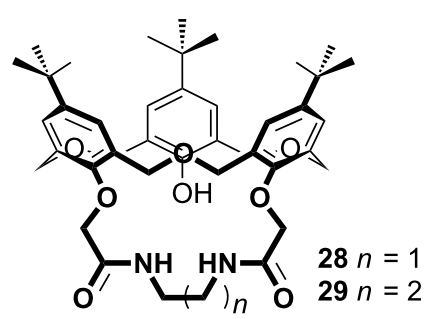

Scheme 16: Synthesis of strapped oxacalix[3]arene derivatives 28 and 29: (i) $N, N^{\prime}$-Bis(chloroacetyl)-1,2-ethylenediamine or $N, N^{\prime}$-bis(chloroacetyl)-1,3-propylenediamine, $\mathrm{K}_{2} \mathrm{CO}_{3}$, acetone [43].

can be attached, the upper rim can also function as a molecular recognition centre. The cavity created by the lipophilic phenolic units, particularly when held in place through allosteric effects of lower-rim substituents bound to metals, can accommodate a number of quaternary ammonium ions or buckminsterfullerene, $\mathrm{C}_{60}$. Consequently, the ability to vary the upper rim functional groups after cyclization is of some interest.

3.2.1 Asymmetric oxacalix[3]arenes: Using the synthetic routes described by Gutsche or Hampton it is possible to create oxacalixarenes with a range of upper-rim groups [14,15]; however, these methods can only yield threefold symmetric oxacalix[3] arenes. In order to introduce other groups and create asymmetric derivatives it is necessary to go through a stepwise synthetic route. Fortunately the strategy described by Fuji in 1998 [19] can be used to prepare linear trimers in which two or three different substituents are present. Using this method it was possible to prepare chiral oxacalix[3] arenes incorporating $t$ - $\mathrm{Bu}$, $\mathrm{iPr}, \mathrm{Et}$ or $\mathrm{H}$ in the para-position of the phenolic moieties, as seen in example $\mathbf{3 0}$ in Figure 11 [45].

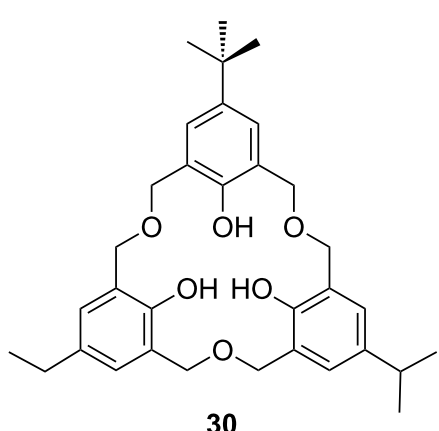

30

Figure 11: A chiral oxacalix[3]arene [45]

The enantiomers can be separated by a chiral HPLC column and give opposite circular dichroic spectra, and can be crystallized out for structural characterization. X-ray crystallography was again able to determine the structure of compound $\mathbf{3 0}$ (Figure 12).

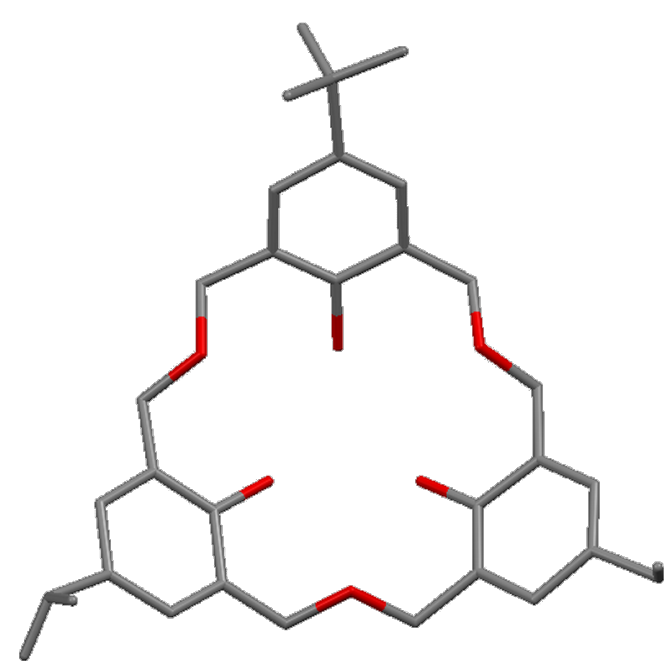

Figure 12: X-ray crystal structure of asymmetric oxacalix[3]arene 30 incorporating $t-\mathrm{Bu}$, iPr and Et groups (CCDC ID 108839) [19].

The work was extended in 2001 [21], and expanded in 2002 [46] to include a single Br substituent (31), which led to an important advance in oxacalix[3] arene chemistry as debromination of $\mathbf{3 1}$ allowed the introduction of new groups in the vacant para-position via the mono-unsubstituted derivative $\mathbf{3 2}$ as shown in Scheme 17. The route introduced nitro (33), azide (34), imidazole (35), phthalimide (36), cyano (37) and methoxyether (38) groups, linked to one of the oxacalix[3]arene rings by a methylene spacer.

As noted earlier, in Scheme 3, Komatsu's diformylphenol approach also generates symmetric and asymmetric oxacalix[n]arenes, where $n=3$ or 4 [22]. 

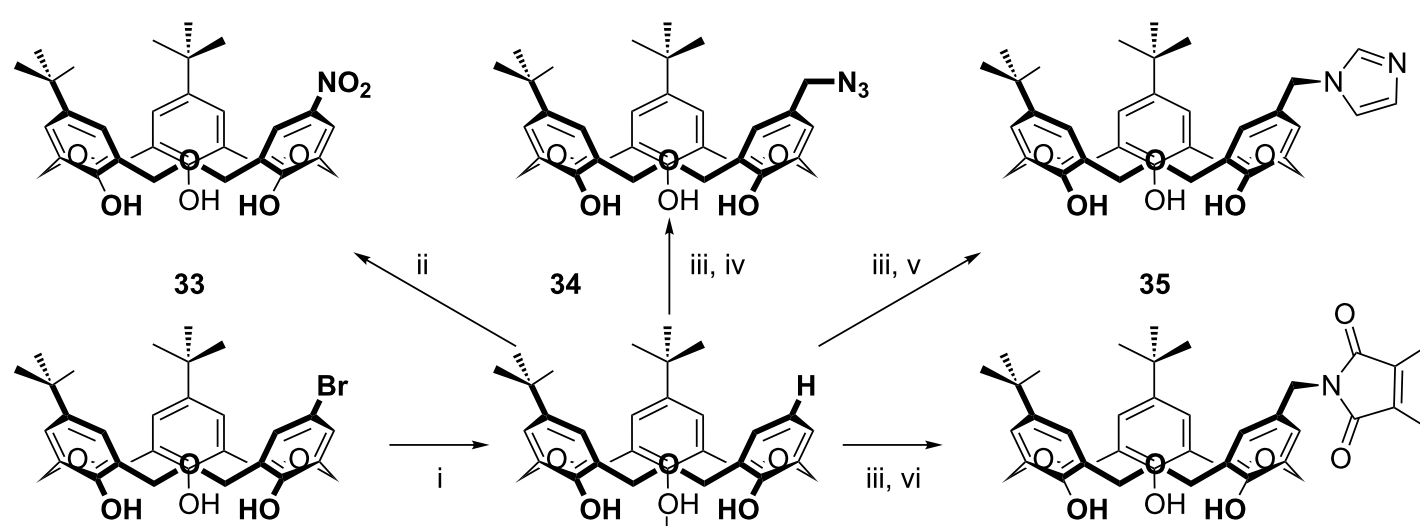

iii, iv
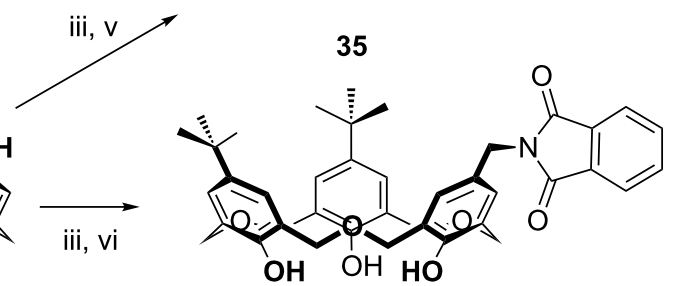

31

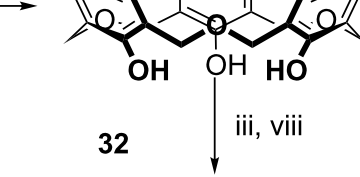

iii, vi

OH OH HO

38

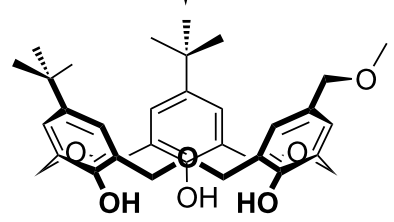

iii, vii

36

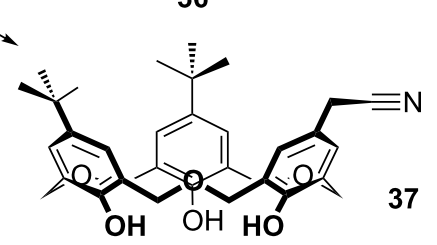

Scheme 17: Reactions of an oxacalix[3]arene incorporating an upper-rim $\mathrm{Br}$ atom with (i) $\mathrm{Pd}(\mathrm{OAc})_{2}, \mathrm{PPh}_{3}, \mathrm{HCO}_{2} \mathrm{H}, \mathrm{Et}_{3} \mathrm{~N}$; (ii) $\mathrm{NH}_{4} \mathrm{NO}_{3}$, acetic anhydride; (iii) $\mathrm{Et}_{2} \mathrm{NH}, \mathrm{H}_{2} \mathrm{CO}$ (aq), $\mathrm{AcOH}$, Mel; (iv) $\mathrm{NaN}_{3}$; (v) imidazole; (vi) potassium phthalimide; (vii) $\mathrm{NaCN}$; (viii) $\mathrm{NaOMe}$ [46].

3.2.2 Upper-rim esters and their reactions: Formation of the oxacalix[3] arene 3k with an upper-rim ester [47-49] makes further derivatives accessible by cleavage of the ester to leave the carboxylic acid $\mathbf{3 9}$ as shown in Scheme 18.<smiles>CCCCCCCCCOCc1cc(C(=O)OCC)cc(C)c1O</smiles>

3k<smiles>COCc1cc(C(=O)O)cc(C)c1O</smiles>

39
Scheme 18: Synthesis of acid 39: (i) $\mathrm{NaOH}, \mathrm{EtOH} / \mathrm{H}_{2} \mathrm{O}, \mathrm{HCl}$ (aq) [47].

Shinkai used this methodology to prepare dimeric oxacalix[3]arene capsules linked by 1,4-xylylenediamine spacers. Derivatives of 39, protected at the lower rim by methyl or $\mathrm{N}, \mathrm{N}$-diethylamide groups, were coupled to mono- $t$-Bocprotected 1,4-xylylenediamine. Subsequent deprotection and reaction with a second equivalent of the oxacalixarene acid gave the dimeric compound (capsule-40) shown in Figure 13. A nonencapsulating analogue was prepared through reaction of the acid derivative with benzylamine. The overall yield from the oxacalix[3]arene is less than $5 \%$, but, given that the dimeriza- tion proceeds in only $14 \%$, this is nevertheless quite impressive. However, in addition to the formation of the molecular capsule, a self-threaded dimer (rotaxane-40) was also isolated, which had resulted from an upper-rim substituent threading through the central cavity during dimerization. The existence of the rotaxane structure was deduced from the complexity of the patterns observed in the ${ }^{1} \mathrm{H}$ NMR spectrum compared to that of the capsule. A similar strategy was adopted to incorporate porphyrin linkers between two oxacalix[3]arenes, but, due to the size of the porphyrins and their rigidity, only the capsular form was found [50]. Treatment with zinc(II) acetate introduced three equivalents of the metal, one for each porphyrin unit.

3.2.3 Capping the upper rim: Capping the upper rim is also possible, as shown by Araki in 2000, through a complex synthetic pathway starting from bromooxacalix[3] arene [51]. As shown in Scheme 19, oxacalix[3] arene 3f was treated with methyl iodide in the presence of $\mathrm{NaH}$ in THF at reflux to afford its methyl ether $\mathbf{4 1}$ in $41 \%$ yield. With the lower rim protected, the upper rim was converted to the aldehyde $\mathbf{4 2}$ and then reduced to the methylol 43. Reaction with 1,3,5-tris(bromomethyl)benzene in a boiling suspension of $\mathrm{NaH}$ in THF/DMF afforded the upper-rim capped compound 44 in $26 \%$ yield. The sulfur-bridged analogue $\mathbf{4 5}$ was prepared in $36 \%$ yield by bromination of the methylol-terminated oxacalix[3]arene, employing $\mathrm{PBr}_{3}$, and coupling with 1,3,5-tris(methanethiol)benzene in the presence of $\mathrm{Cs}_{2} \mathrm{CO}_{3}$ in THF. 


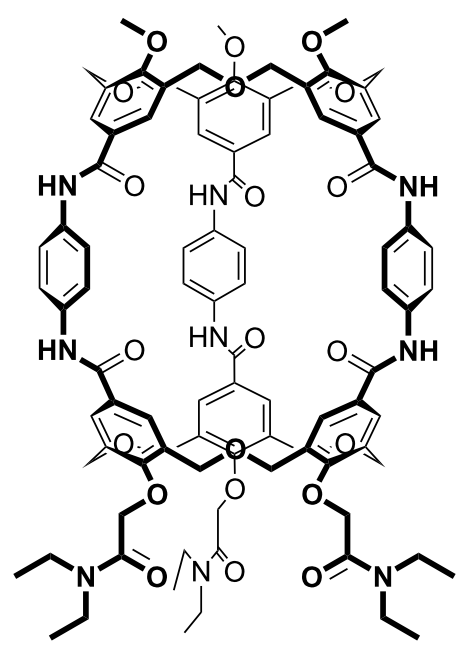

capsule-40

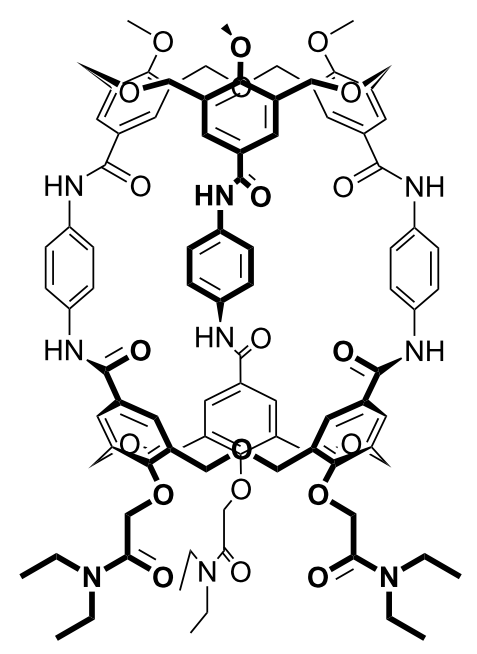

rotaxane-40

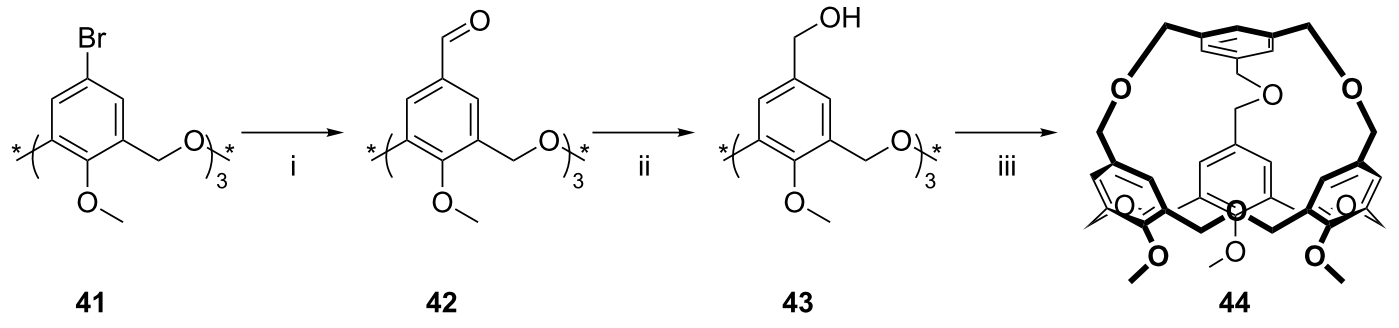

Scheme 19: Capping the upper rim: (i) $t$-BuLi, THF, $-78^{\circ} \mathrm{C}$; (ii) $\mathrm{NaBH}_{4}, \mathrm{THF} / \mathrm{EtOH}$; (iii) 1,3,5-tris(bromomethyl)benzene, $\mathrm{Na}_{2} \mathrm{CO}_{3}, \mathrm{DMF}[51]$.

3.2.4 Upper-rim coordination chemistry: The functionalization of the upper rims of oxacalix[3] arenes has also been achieved through classical inorganic coordination chemistry. Shinkai reported that the reactions of 4- and 3-pyridyloxacalix[3] arenes, protected on the lower rims by esters or methyl ethers, with [1,3-(diphenylphosphine)propane]palladium(II) salts gave dimeric capsules linked by three $\mathrm{Pd}(\mathrm{II})$ ions at the 4-pyridyl groups (46, Figure 14) or 3-pyridyl groups (47) $[52,53]$. The twist inherent in pyridylphenols, and by extension oxacalix[3] arenes incorporating these motifs, was expected to result in two chiral $(M$ and $P$ ) forms of the capsules. The addition of $\mathrm{Na}^{+}$appeared to enhance the twisting of capsule 46, presumably through an allosteric effect that occurred when the cations bound to the lower-rim esters, as indicated by increasingly complex ${ }^{1} \mathrm{H}$ NMR patterns. When 46 bound to $S$-2-methylbutylammonium triflate, the presence of a chiral complex was confirmed by circular dichroism [53].

\section{Oxacalix[3]arene complexes}

\subsection{Complexation by parent oxacalix[3]arenes}

4.1.1 Receptors for ammonium cations: The symmetric cavity of the oxacalix[3] arenes, with three $\mathrm{CH}_{2} \mathrm{OCH}_{2}$ bridges and electron-rich aromatic groups, makes them attractive macrocycles to bind ammonium cations. The affinity of $\mathbf{3 a}$ for acetylcholine and several other quaternary ammonium ions was investigated by Masci in 1995 [54] who found that $K_{\text {assoc }}$ values in $\mathrm{CDCl}_{3}$ were modest, ranging from $38 \mathrm{M}^{-1}$ for $N, N, N$ trimethylanilinium to $90 \mathrm{M}^{-1}$ for $N, N$-dimethylpyrrolidinium, but significantly greater than those of the dihomocalix[4]arene and tetrahomooxacalix[4]arene analogues.

4.1.2 Alkali-metal complexes: The parent oxacalix[3]arenes (calixarenes with free $\mathrm{OH}$ groups) show little ability to bind alkali metals, and extraction studies from water to $\mathrm{CH}_{2} \mathrm{Cl}_{2}$ showed that this ability was enhanced only in the presence of strong bases [15]. Hampton's purification of $\mathbf{3 a}$ involved the 

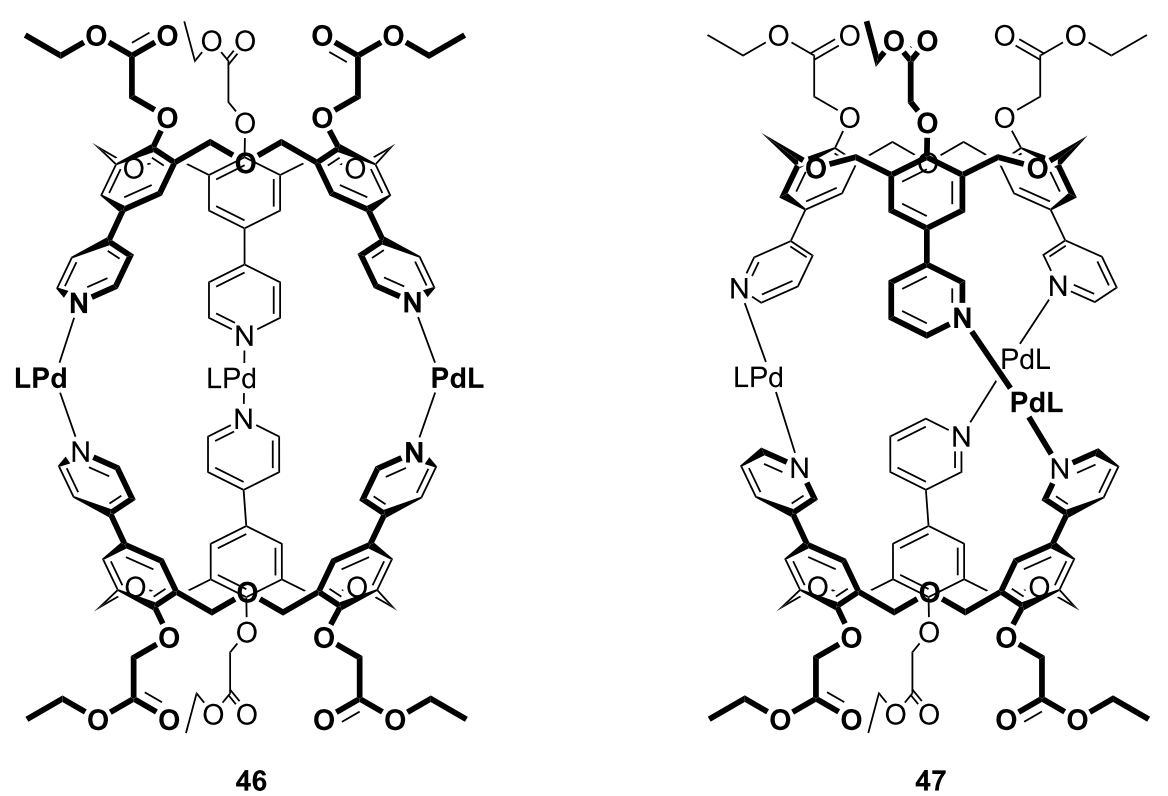

Figure 14: Oxacalix[3]arene capsules 46 and 47 formed through coordination chemistry $[52,53]$.

formation and precipitation of the $\mathrm{Na}^{+}$salt, which would seem to indicate a significant affinity for metal cations. Surprisingly, only para-chlorooxacalix[3]arene, $\mathbf{3 e}$, was found to bind alkali metals and then only when triethylamine was used to promote salt formation. The binding constants were determined by ${ }^{1} \mathrm{H}$ NMR as $0.39 \mathrm{M}^{-1}$ for $\mathrm{Na}^{+}, 0.32 \mathrm{M}^{-1}$ for $\mathrm{K}^{+}$and $0.11 \mathrm{M}^{-1}$ for $\mathrm{Li}^{+}$in the presence of 10 equiv of the triflate salts. However, those oxacalixarenes form stronger complexes with transition, lanthanide and uranyl cations.

Cragg employed the quartz-crystal-microbalance technique to investigate binding by $\mathrm{Na}^{+}, \mathrm{K}^{+}$and $\mathrm{Ca}^{2+}$ to $\mathbf{3 a}$ and $\mathbf{3 k}$ [48] Again, $\mathrm{Na}^{+}$was bound preferentially, with computer models suggesting that this was due to the depth to which the cation was drawn into the macrocyclic cavity when in the cone conformer.

4.1.3 Transition-metal complexes: The first example of transition-metal binding to an oxacalix[3]arene was Hampton's variable temperature ${ }^{1} \mathrm{H}$ NMR investigation of the interactions between titanium(IV) species and 3a [55]. In the absence of crystallographic evidence the NMR splitting patterns were compared to simulated spectra. At ambient temperature the NMR-derived symmetry was $C_{3 v}$, matching that of the macrocycle, but upon cooling an asymmetric $C_{S}$ symmetry emerged. It was proposed that rapid interconversion between isomers occurred by a "turnstile" or Berry-pseudorotation mechanism. A subsequent paper from the group reported the crystal structure of the titanium(IV) isopropoxide ( $\left.\mathrm{Ti}(\mathrm{PPrO})_{4}\right)$ complex [56]. The structure was dimeric; each macrocycle was present as the trianion bound to the titanium by all three oxygens and pulled slightly into the cavity by $\mathrm{iPrO}^{-}$. The paper also reported the result of a reaction between the lithium salt of $\mathbf{3 b}$ and vanadyl chloride $\left(\mathrm{VOCl}_{3}\right)$. Based on powder diffraction and ${ }^{51} \mathrm{~V}$ NMR data it was proposed that the VO group bound within the macrocyclic cavity, by analogy to the Ti(IV) complex, and that these units formed linear aggregates held together by $\mathrm{V}=\mathrm{O} \cdots \mathrm{V}=\mathrm{O}$ interactions. Ten years later, Redshaw was able to prove Hampton's assertion regarding the structure by X-ray analysis of the VO complex shown in Figure 15 [57].

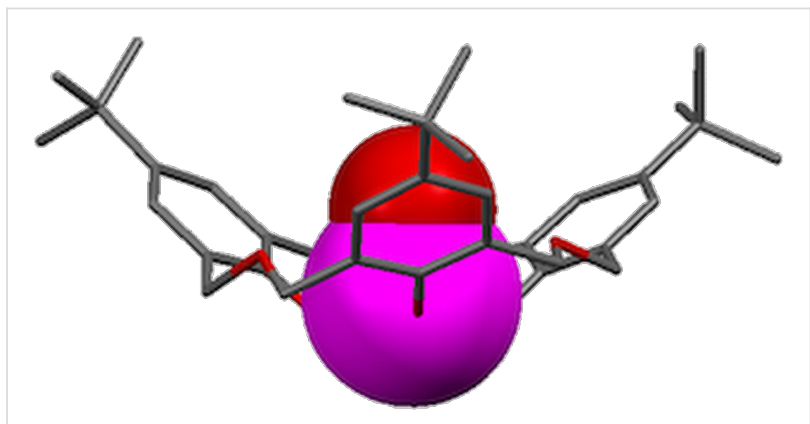

Figure 15: X-ray crystal structure of the $3 \mathrm{~b}$-vanadyl complex (CCDC ID 240185) [57].

Katz used calixarenes to disperse reactive titanium on silica in order to prepare a catalytically active surface [58]. While $p$-tertbutylcalix[4]arene appeared to work successfully, oxacalix[3]arene 3a first bound titanium and was then cleaved to give an acyclic surface-bound product with free methyl and aldehyde termini (Scheme 20). 


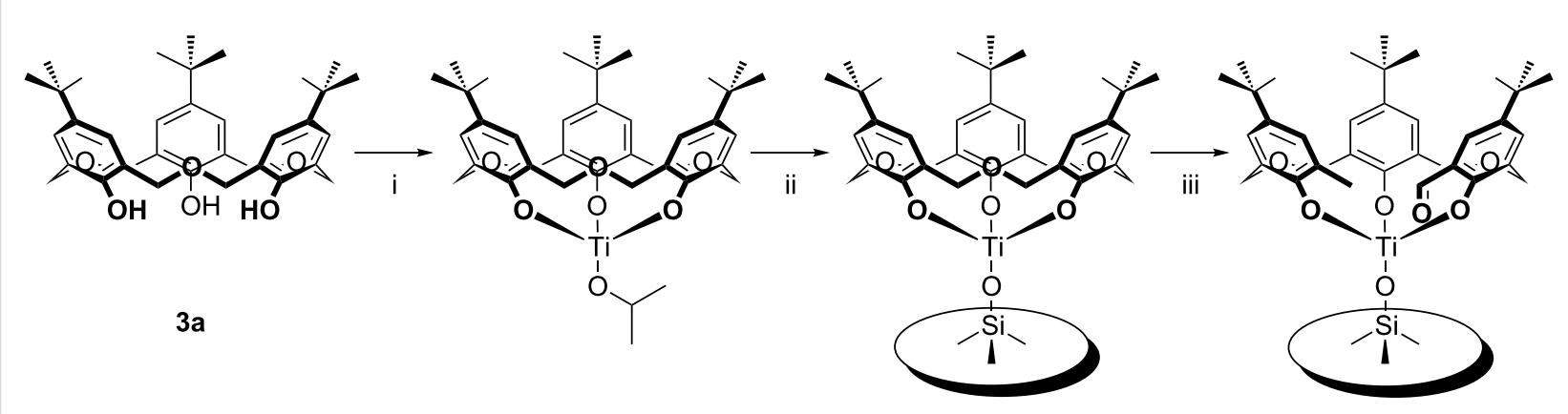

Scheme 20: Effect of $\mathrm{Ti}(\mathrm{IV}) / \mathrm{SiO}_{2}$ on 3a: (i) $\mathrm{Ti}(\mathrm{OiPr})_{4}$, toluene; (ii) triphenylsilanol, toluene; (iii) partially dehydroxylated silica gel, toluene [58].

Klufers prepared complexes of $\mathbf{3 b}, \mathbf{3} \mathbf{d}$ and $\mathbf{3 k}$ through reaction of the macrocycles with $\left(\mathrm{Et}_{3} \mathrm{~N}\right)_{2}\left[\operatorname{Re}(\mathrm{CO})_{3} \mathrm{Br}_{3}\right]$ in acetonitrile [49]. The X-ray crystal structures of the complexes with $\mathbf{3 b}$ and 3d showed binding by $\operatorname{Re}(\mathrm{CO})_{3}$ to two deprotonated phenolic oxygen atoms as shown in Figure 16. Reaction with ester derivative $3 \mathbf{k}$ at $85{ }^{\circ} \mathrm{C}$ resulted in decomposition of the macrocycle.

4.1.4 Lanthanide complexation: The first study of the binding affinities of lanthanides for oxacalix[3] arenes was in 1995 when Hampton reported the crystal structure and dynamic behaviour of a scandium(III) complex of 3a [59]. Later, the X-ray structures of lanthanum, lutetium and yttrium complexes with the same macrocycle showed 2:2 complexes between the cations and macrocycles [60]. In these structures the lanthanides are either six-coordinate, with distorted octahedral metal centres, or eight-coordinate, as in the structure illustrated in Figure 17.

The same group calculated the apparent binding constants of metal triflates with 3a and 3e [61]. Results showed that the binding constants for $\mathbf{3 e}$ were slightly higher than $\mathbf{3 a}$ and that

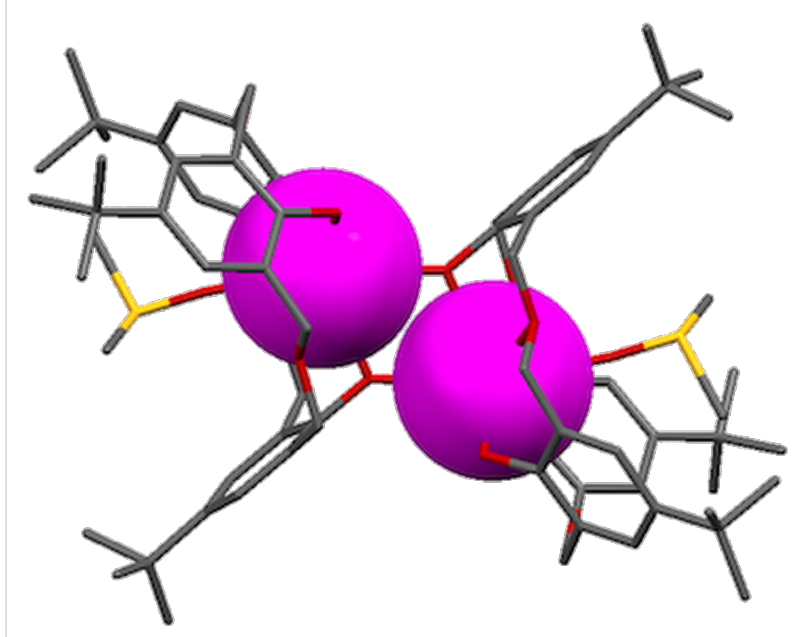

Figure 17: X-ray crystal structure of the $\mathrm{La}_{2} \cdot 3 \mathrm{a}_{2}$ complex (CSD ID TIXXUT) [60].

the strength of binding increased in the sequence $\mathrm{Ca}^{2+}, \mathrm{Na}^{+}$, $\mathrm{Li}^{+}<\mathrm{Mg}^{2+}<\mathrm{La}^{3+}<<\mathrm{Y}^{3+}<\mathrm{Lu}^{3+}<<\mathrm{Sc}^{3+}$. To reinforce this, the transporting ability of the oxacalixarenes was investigated.

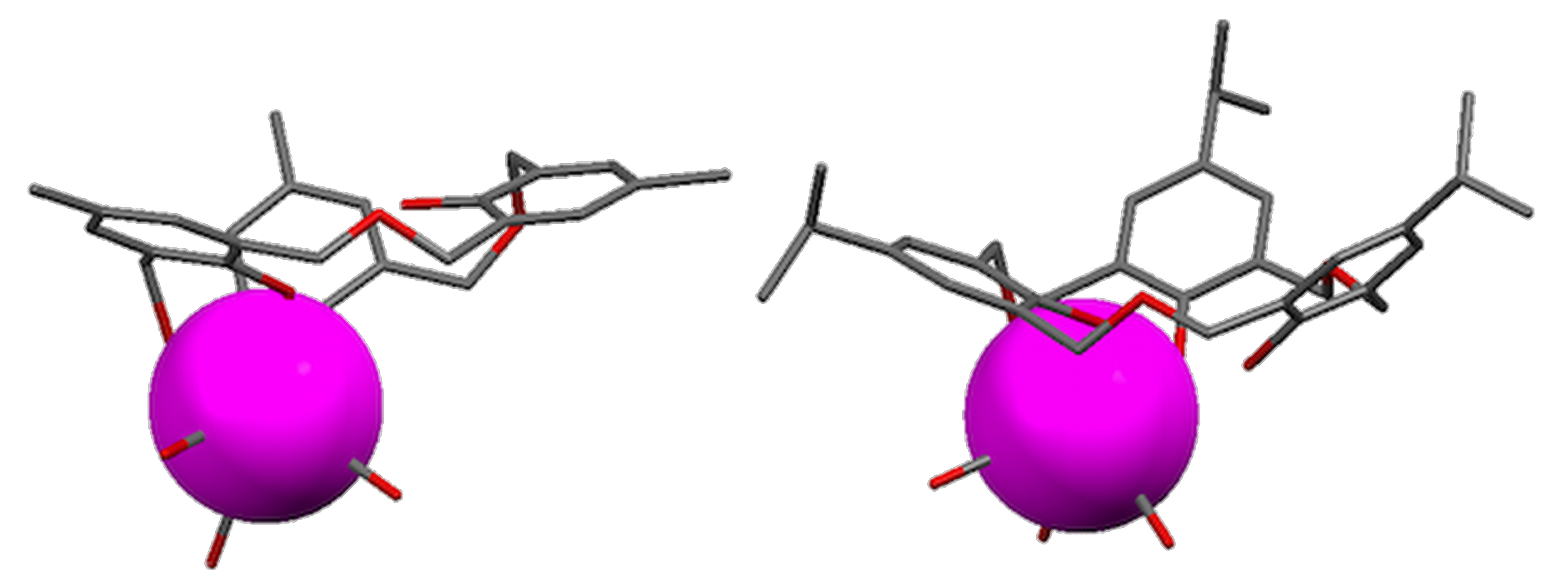

Figure 16: X-ray crystal structures of oxacalix[3]arene complexes with rhenium: $\mathbf{3 b} \cdot \operatorname{Re}(\mathrm{CO})_{3}\left(\mathrm{CCDC} I \mathrm{ID} 620981\right.$, left) and $\mathbf{3 d} \cdot \operatorname{Re}(\mathrm{CO})_{3}(\mathrm{CCDC}$ ID 620982, right) [49]. 
Aqueous/organic/aqueous liquid-membrane transport experiments were undertaken with both oxacalix[3]arenes in order to determine their cation selectivities. No transport of $\mathrm{Li}^{+}$or $\mathrm{Mg}^{2+}$ was observed, but $3 \mathrm{e}$ transported $44 \%$ of the $\mathrm{Sc}^{3+}$ over $24 \mathrm{~h}$ when a mixture of three cations $\left(\mathrm{Sc}^{3+}, \mathrm{Mg}^{2+}\right.$ and $\left.\mathrm{Li}^{+}\right)$was used as the source phase.

4.1.5 Chelating behaviour with uranium: Complexation of the uranyl cation by oxacalix[3] arenes has been ongoing since 1999 when Thuéry reported a complex of uranyl $\left(\mathrm{UO}_{2}{ }^{2+}\right)$ and 3a [62]. The X-ray crystal structure showed that the cation was threaded through a single macrocycle in what was, at the time, an unprecedented pseudotrigonal geometry, which included a weak interaction between the nitrogen of $\mathrm{Et}_{3} \mathrm{~N}$ and a uranyl oxygen (Figure 18). Masci and Thuéry later reported more tetrahedrally and pentagonally distorted structures with $\mathbf{3 a}$ and $\mathbf{3 b}$ [63]. The nature of the alkylammonium counterion appeared to be influential in determining the final geometry around the uranium centre, yet in some cases it did not interact with the uranyl moiety (Figure 18).

Replacing the alkylammonium cations with protonated [2.2.2] cryptand resulted in 1:1 and 2:1 complexes in which the uranyl-oxacalix[3] arene moiety acts as a recognition site for the [2.2.2] cryptand [64]. Figure 19 shows the crystal structure of the $2: 1$ complex.

\subsection{Binding properties of oxacalix[3]arene deriva- tives}

One of the most important features of calixarenes in general and oxacalix[3] arenes in particular is their vast ability to selectively bind and carry ions and neutral species. This is achieved mainly with lower-rim derivatives in solution.

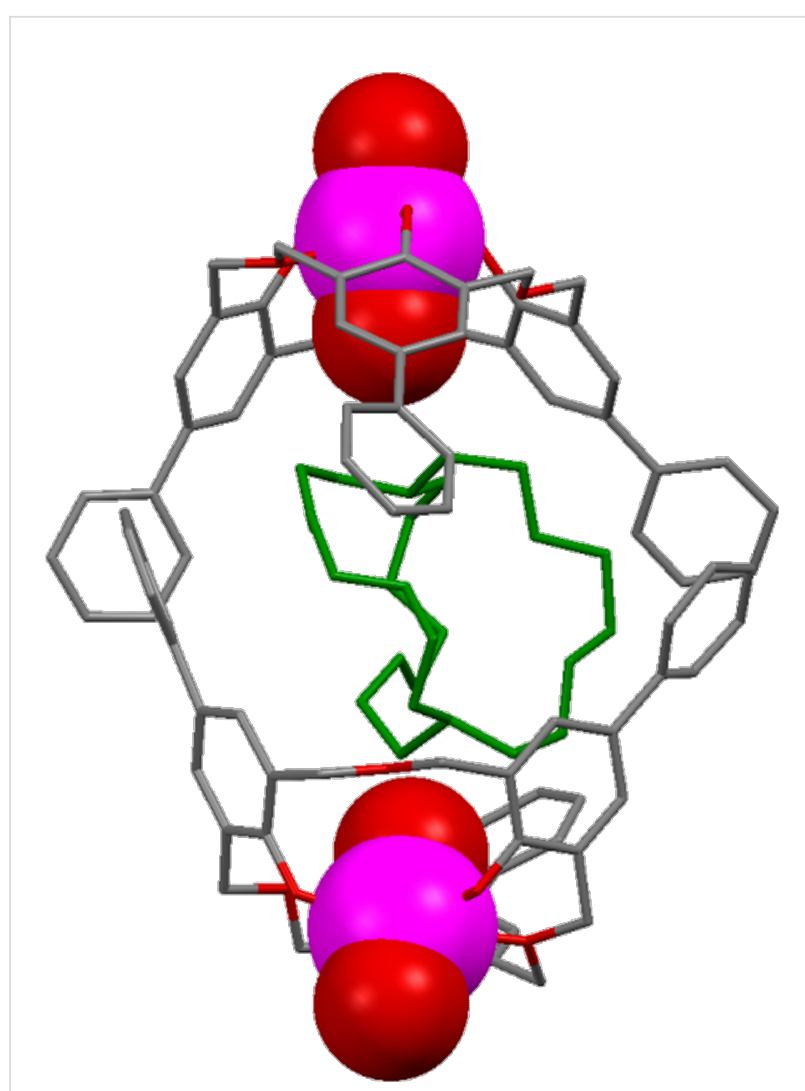

Figure 19: X-ray crystal structure of a supramolecule comprising two $\left[\mathbf{3 g} \cdot \cup_{2}\right]^{-}$complexes that encapsulate a diprotonated cryptand (CCDC ID 181044) [64].

4.2.1 Receptors for ammonium cations: Although the simple parent oxacalix[3] arene $\mathbf{3 a}$ is able to bind quaternary ammonium ions (as described above), several derivatives have also been studied with respect to these and other ammonium ions. Extrac-

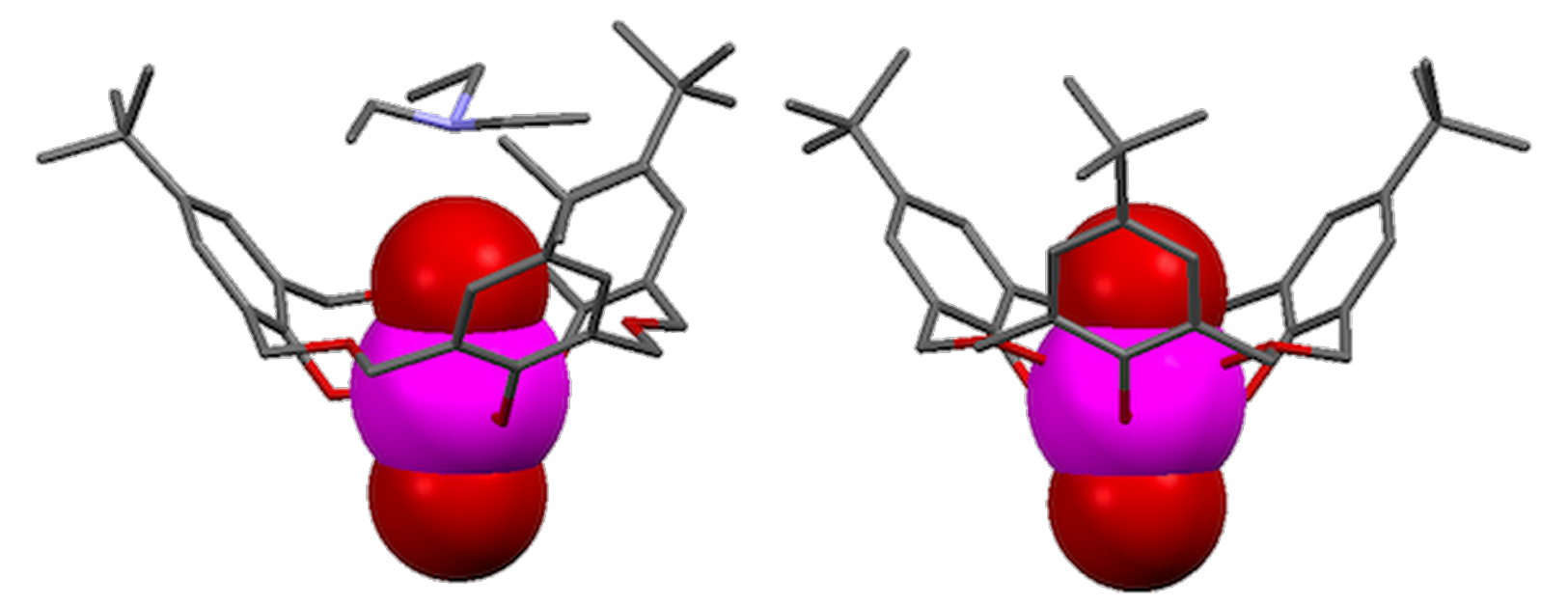

Figure 18: X-ray crystal structures of [3a-UO $]^{-}$with a cavity-bound cation (CCDC ID 135575, left) and without a coordinated cation (CCDC ID 181042 , right) $[62,63]$. 
tion studies from alkaline aqueous picrate solutions into $\mathrm{CH}_{2} \mathrm{Cl}_{2}$ indicated that the $n$-butyl ether derivative $\mathbf{1 0}$ showed a high affinity for $n-\mathrm{BuNH}_{3}{ }^{+}(82 \% E)$ as postulated by the authors, because both host and guest possess the same $C_{3}$-symmetry [24]. Ethyl ester 12a was more efficient at extracting $n-\mathrm{BuNH}_{3}{ }^{+}$ picrate from water into $\mathrm{CH}_{2} \mathrm{Cl}_{2}$ than its calix[4] arene analogue was, in both the cone $(77 \%$ vs $24 \%$ E) and partial-cone ( $42 \%$ vs $6 \% E$ ) conformers [29]. In a wider study, Yamato determined extraction data for $\mathbf{1 7 a}$ with $n-\mathrm{BuNH}_{3}{ }^{+}$picrate $(98 \% E$ cone vs 93\% E partial-cone), $\mathrm{iBuNH}_{3}{ }^{+}$picrate $(48 \% E$ cone vs $37 \% E$ partial-cone) and $t$ - $\mathrm{BuNH}_{3}{ }^{+}$picrate $(35 \%$ E cone vs $14 \% E$ partial-cone) [34]. The hexaamide derivative $\mathbf{2 0}$ bound $n$ - $\mathrm{BuNH}_{3}{ }^{+}$well, and an anion dependence was determined; $K_{\text {assoc }}$ values in $\mathrm{CDCl}_{3}$ were $536 \pm 32 \mathrm{M}^{-1}$ for $\mathrm{Cl}^{-}$and $230 \pm 17 \mathrm{M}^{-1}$ for $\mathrm{Br}^{-}$[37].

Studies of the $C_{3}$ symmetrically capped triamide 13 reported that this derivative acts as a well-preorganized host for binding primary ammonium ions, such as phenylalanine methyl ester [31]. Chiral recognition of optically active primary alkyl ammonium ions was also obtained with an ether derivative of oxacalix[3] arene 3a with one methyl and two $n$-butyl lower-rim substituents 49, as shown in Figure 20 [65]. The compound was shown to exist in (+) and (-) enantiomers, and in a partial-cone conformation, proof of which came from X-ray crystallography. The compound bound to $\alpha$-amino acid ethyl esters and 1 -arylethylamines with the methoxy and one $n$-butoxy oxygen. The (-)-4-tert-butyloxacalix[3] arene derivative bound L-alanine ethyl ester and L-phenylalanine ethyl ester better than their enantiomers, with association constants of $4500 \mathrm{M}^{-1}$ and $2000 \mathrm{M}^{-1}$, respectively. (R)-1-Phenylethylamine and $(R)-1$ naphthylethylamine cations were bound more strongly by the (+)-enantiomer.

Allosteric effects can also be employed to affect the binding of ammonium cations. Katoh's $N$-hydroxypyrazinone-containing oxacalix[3] arene 23 extracted $n-\mathrm{BuNH}_{3}{ }^{+}$picrate and $t-\mathrm{BuNH}_{3}{ }^{+}$ picrate better in the presence of $\mathrm{Ga}^{3+}$, indicating cooperation between the two binding sites [38]. The association constant for $n$ - $\mathrm{HexNH}_{3}{ }^{+}$picrate was found to be $4375 \mathrm{M}^{-1}$, but when $\mathrm{Ga}^{3+}$ was present this dropped to $2833 \mathrm{M}^{-1}$, suggesting that the macrocyclic cavity, while preorganized for the smaller cations, was too rigid for the extended ammonium cation.

One of the more unusual derivatives to have been prepared, 50, incorporates an $\mathrm{N}$-pyridinium dye on one of the upper-rim positions, which, in combination with the phenolic unit of the macrocycle, forms a proton-ionizable Reichardt dye, illustrated in Figure 21 [66]. The other $p$-tert-butyl substituted phenols are blocked from ionization, as are the methyl ethers. The native oxacalix[3] arene dye is pale green and gives no response to

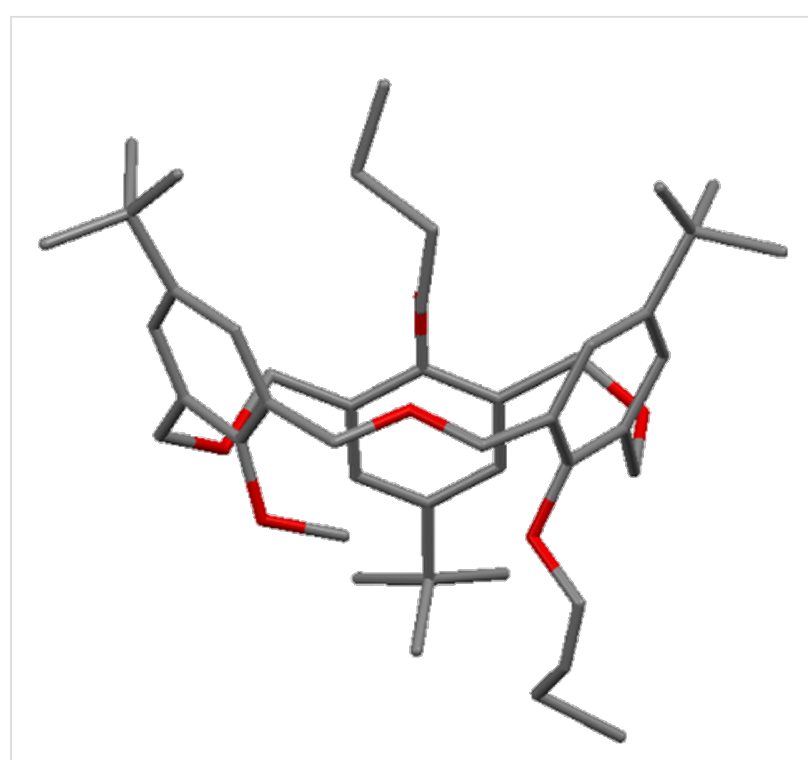

Figure 20: X-ray crystal structure of oxacalix[3]arene 49 capable of chiral selectivity (CSD ID HIGMUF) [65].

benzylamine $\left(\mathrm{BzNH}_{2}\right)$ or triethylamine $\left(\mathrm{Et}_{3} \mathrm{~N}\right)$, but cyclohexylamine $\left(c-\mathrm{HexNH}_{2}\right)$ and $n$-butylamine $\left(n-\mathrm{BuNH}_{2}\right)$ bind with a concomitant colour change to blue.

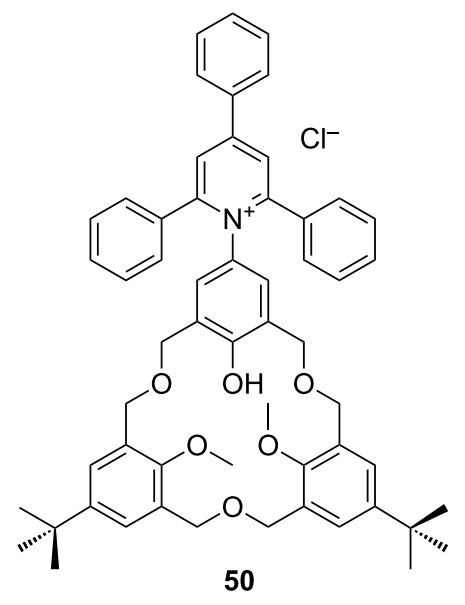

Figure 21: The structure of derivative $\mathbf{5 0}$ incorporating a Reichardt dye [66].

4.2.2 Alkali metals: The ionophoric properties of the conformationally mobile ethyl ether of $\mathbf{3 a}(\mathbf{8})$ and both cone and partialcone $n$-butyl ether $\mathbf{1 0}$ derivatives toward alkali-metal cations were estimated by extraction experiments from alkaline aqueous picrate solutions to $\mathrm{CH}_{2} \mathrm{Cl}_{2}$ [24], with the latter showing some preference for $\mathrm{K}^{+}(59 \% E)$ over $\mathrm{Na}^{+}(6 \%)$ and $\mathrm{Cs}^{+}(35 \%)$. 
Replacement of the alkyl groups by residues with additional binding sites, such as the carbonyl group, strongly affects the binding ability of calixarene derivatives. Thus, the binding properties of derivatives containing esters, amides and ketones, have been assessed. Extraction studies performed under the same conditions as described above reported that cone ester 12a shows high selectivity for $\mathrm{Na}^{+}$whereas the partial-cone conformer shows $\mathrm{K}^{+}$selectivity (Table 1) [29]. Similar extraction experiments performed with amide 17a [34] reported that this derivative is a better phase-transfer agent than 12a, but shows the same trend as 12a: cone-17a exhibits the highest preference for $\mathrm{Na}^{+}$, while partial-cone-17a prefers $\mathrm{K}^{+}$ (Table 1).

\begin{tabular}{|c|c|c|c|c|}
\hline & $\mathrm{Li}^{+}$ & $\mathrm{Na}^{+}$ & $\mathrm{K}^{+}$ & $\mathrm{Cs}^{+}$ \\
\hline cone-12a & 7 & 79 & 64 & 49 \\
\hline paco-12ab & 0 & 26 & 88 & 82 \\
\hline cone-17a & - & 93 & 72 & - \\
\hline paco-17a & - & 28 & 73 & - \\
\hline
\end{tabular}

${ }^{\mathrm{a} D a t a}$ adapted from references [29] and [34]. ${ }^{\mathrm{b}}$ partial-cone denoted as paco.

The association constants, $K_{\text {assoc }}$, for both derivatives (12a and 17a) were determined in $\mathrm{THF} / \mathrm{CHCl}_{3}(1: 1)$ at $25{ }^{\circ} \mathrm{C}$ by UV absorption spectrophotometry (Table 2) [25].

\begin{tabular}{|c|c|c|c|c|c|c|c|}
\hline & $\mathrm{Na}^{+}$ & $\mathrm{K}^{+}$ & $\mathrm{Rb}^{+}$ & $\mathrm{Cs}^{+}$ & $\mathrm{Mg}^{2+}$ & $\mathrm{Ca}^{2+}$ & $\mathrm{Ba}^{2+}$ \\
\hline cone-12a & 4 & 4.7 & 4.2 & 3.9 & $<2$ & $<2$ & $<2$ \\
\hline cone-17a & $>7$ & 5.9 & 5.5 & 5.2 & 4.9 & $>7$ & $>7$ \\
\hline paco-17ab & 5.1 & 6.2 & 6.0 & 5.5 & - & - & - \\
\hline
\end{tabular}

aData adapted from reference [25]. ${ }^{\mathrm{b}}$ partial-cone denoted as paco.

Marcos $[39,67]$ reported binding data for alkali- and alkalineearth-metal cations with 17a and $\mathbf{2 4}$ (Table 3). Extraction studies performed under different conditions than the previous ones (neutral aqueous picrate solutions to $\mathrm{CH}_{2} \mathrm{Cl}_{2}$ ), indicated that both derivatives show similar extraction profiles, although 17a is a much stronger binder than 24. Both exhibit highest selectivity for $\mathrm{Na}^{+}$(50 and $20 \% E$ for $\mathbf{1 7 a}$ and 24, respectively) and $17 \mathbf{a}$ is also a good extractant for $\mathrm{Ba}^{2+}(55 \% E)$.

Derivatives with heteroatoms on the lower rim have also been tested as cation chelators. The binding properties of 2-pyridylmethyloxy derivative 11a in both conformations, have been established [27,68]. Extraction studies from neutral aqueous picrate solutions to $\mathrm{CH}_{2} \mathrm{Cl}_{2}$ showed that, among all the cations studied, the partial-cone conformer is a better extractant than the cone.

As well as simple oxacalix[3]arenes and their derivatives, capped compounds have also been investigated. Association constants for several metal cations were determined for Yamato's lower-rim-capped derivative 18 [33]. Values were found for $\mathrm{Na}^{+}\left(\log K_{\text {assoc }} 5.3\right), \mathrm{K}^{+}\left(\log K_{\text {assoc }} 6.7\right)$ and $\mathrm{Cs}^{+}$ $\left(\log K_{\text {assoc }} 5.8\right)$. This contrasts with $\log K_{\text {assoc }}$ of 7.6 for $n$ - $\mathrm{BuNH}_{3}{ }^{+}$picrate. The extractability of metals from aqueous solution into $\mathrm{CH}_{2} \mathrm{Cl}_{2}$ by Araki's upper-rim-capped derivatives was also determined [51]. The complementary cavity size and the rigid structure of the cage molecule $\mathbf{4 4}$ probably led to the high $\mathrm{Cs}^{+}$selectivity $(\approx 45 \% E$ ) compared to negligible amounts of $\mathrm{Na}^{+}, \mathrm{K}^{+}$or $\mathrm{Rb}^{+}(<5 \% E)$; however, the sulfur-linked compound $\mathbf{4 5}$ failed to extract any cations.

4.2.3 Transition metals: The tris(diphenylphosphine) derivative 26 prepared by Matt [40] was reacted with $\left[\mathrm{Mo}(\mathrm{CO})_{3}(\right.$ cycloheptatriene $\left.)\right]$ to give a complex that was determined to be the symmetrically bound $\mathrm{Mo}(\mathrm{CO})_{3}$ complex involving all three of the phosphorus donors. The oxacalix[3]arene also formed a complex with rhodium. Elemental analysis supported a composition incorporating the $\mathrm{H}-\mathrm{Rh}-\mathrm{C}=\mathrm{O}$ fragment. ${ }^{1} \mathrm{H}$ NMR indicated that this was threaded through the macrocyclic annulus, based on the presence of a peak at $-9.70 \mathrm{ppm}$, and infrared analysis showed a carbonyl absorption band at $1977 \mathrm{~cm}^{-1}$. This suggested an orientation in which the hydrogen was endo, and the carbonyl exo, to the macrocyclic cavity. Gold(I) and silver(I) complexes also form with the cations most likely adopting a trigonal planar $C_{3 v}$

\begin{tabular}{llllllllll} 
Table 3: Percentage extraction of alkali and alkaline earth metal picrates into $\mathrm{CH}_{2} \mathrm{Cl}_{2}$. & & \\
& $\mathrm{Li}^{+}$ & $\mathrm{Na}^{+}$ & $\mathrm{K}^{+}$ & $\mathrm{Rb}^{+}$ & $\mathrm{Cs}^{+}$ & $\mathrm{Mg}^{2+}$ & $\mathrm{Ca}^{2+}$ & $\mathrm{Sr}^{2+}$ & $\mathrm{Ba}^{2+}$ \\
\hline $\begin{array}{l}\text { cone-17a } \\
\text { cone-24}\end{array}$ & 25 & 50 & 32 & 27 & 20 & 17 & 34 & 41 \\
\hline
\end{tabular}

aData adapted from references [67]. bData adapted from reference [39]. 

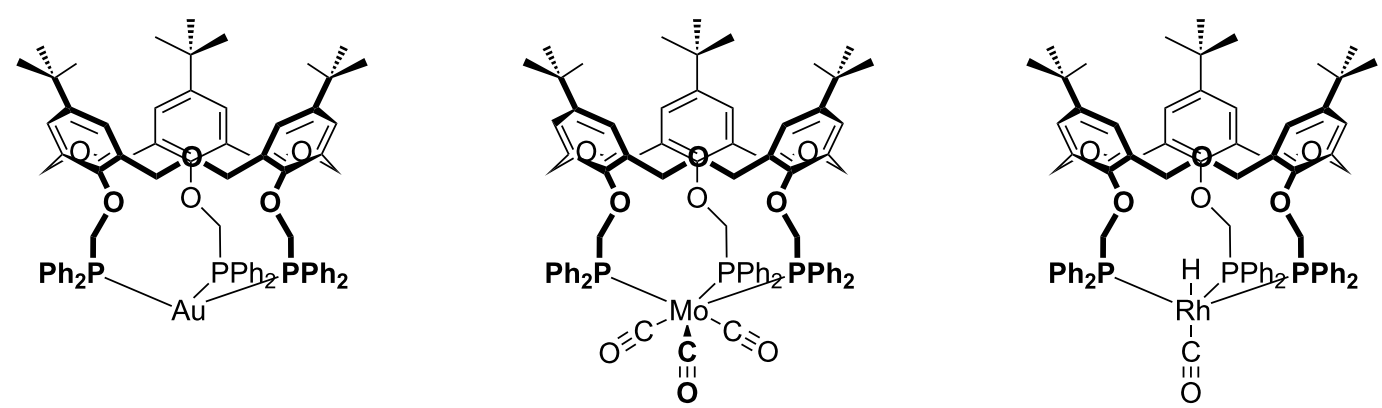

Figure 22: Phosphorylated oxacalix[3]arene complexes with transition metals: (Left to right) $\mathbf{2 6} \cdot \mathrm{Au}, \mathbf{2 6} \cdot \mathrm{Mo}(\mathrm{CO})_{3}$ and $\mathbf{2 6} \cdot \mathrm{RhH}(\mathrm{CO})[40]$.

geometry, as shown in Figure 22, based on the symmetric ${ }^{31} \mathrm{P}$ NMR pattern at ambient temperature. At lower temperatures, however, the $\mathrm{A}_{3} \mathrm{X}$ pattern seen for the silver(I) complex changes to an $\mathrm{A}_{2} \mathrm{BX}$ pattern, indicating that the apparent symmetry is a time-averaged effect.

Cragg reported the reaction of $\mathbf{1 7} \mathbf{a}$ with mercury(II) chloride and the X-ray crystal structure of the product (Figure 23) [69]. The structure revealed that a $\left[\mathrm{HgCl}_{2}\right]_{2}$ fragment bridged between two macrocycles through coordination to one amide group of each. The cations were thus exo to the macrocyclic cavity and represented the first example in which a cation was not bound within the annulus.

Marcos reported on the binding properties and theoretical studies of 17a [67] and 24 [39] with transition and heavy metals. Extraction studies from neutral aqueous picrate solutions to $\mathrm{CH}_{2} \mathrm{Cl}_{2}$ indicated that amide $\mathbf{1 7} \mathbf{a}$ is a good extractant for $\mathrm{Ni}^{2+}, \mathrm{Co}^{2+}$, and $\mathrm{Ag}^{+}$, and mainly for $\mathrm{Pb}^{2+}$ with $80 \% E$. The data in Table 4 also shows that ketone $\mathbf{2 4}$ is a weak extracting agent, with a slight preference for $\mathrm{Ag}^{+}$. This is in agreement with the higher basicity of the carbonyl oxygen in the amide group compared with the ketone group.

4.2.4 Lanthanides: Marcos investigated the lanthanide extraction by both 17a [70] and 24 [39] using the same conditions as described above (Table 5). Ketone $\mathbf{2 4}$ is a poor phase-transfer agent ( $\% E$ ranges from 5 to 7 ), while amide 17 a clearly discriminates between the light and heavy lanthanides. The

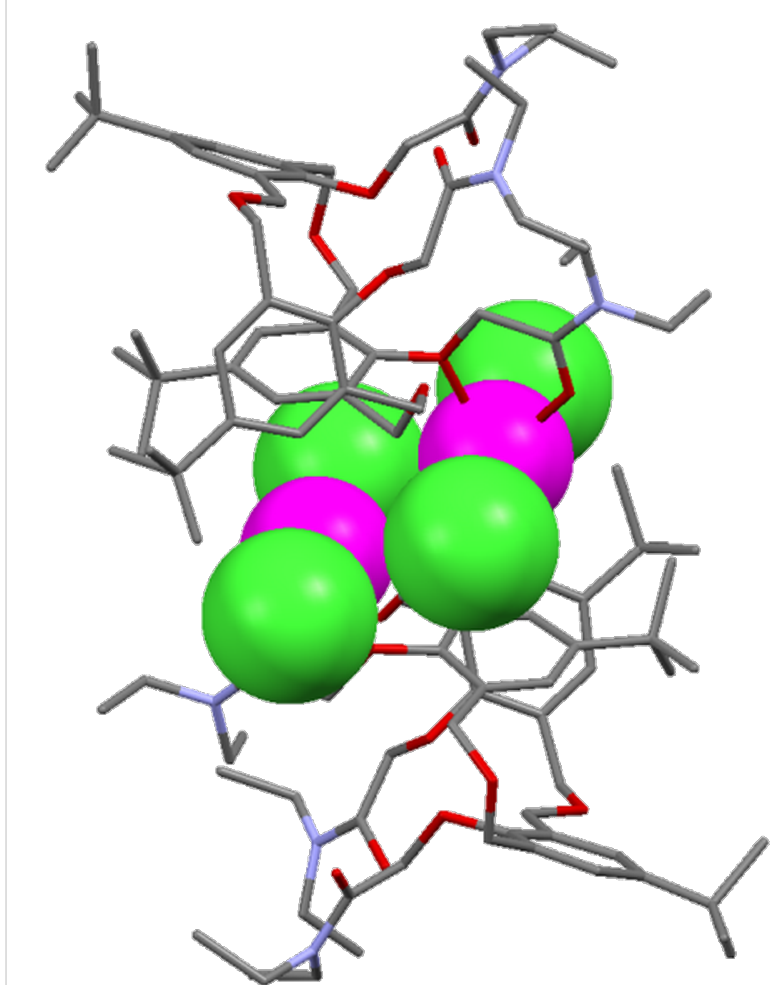

Figure 23: X-ray crystal structure of $\left[17 \mathrm{a} \cdot \mathrm{HgCl}_{2}\right]_{2}(\mathrm{CCDC}$ ID 168653) [69].

lower-weight cations, such as $\mathrm{Ce}^{3+}, \mathrm{Pr}^{3+}$ and $\mathrm{Nd}^{3+}(34 \% E)$ are preferred over the heavier, such as $\mathrm{Er}^{3+}$ and $\mathrm{Yb}^{3+}(13 \% E)$. The stability constants for the 1:1 complexes with $\mathbf{1 7 a}$ were also

Table 4: Percentage extraction of transition- and heavy-metal picrates into $\mathrm{CH}_{2} \mathrm{Cl}_{2}$.

\begin{tabular}{llllllllll} 
& $\mathrm{Mn}^{2+}$ & $\mathrm{Fe}^{2+}$ & $\mathrm{Co}^{2+}$ & $\mathrm{Ni}^{2+}$ & $\mathrm{Cu}^{2+}$ & $\mathrm{Zn}^{2+}$ & $\mathrm{Ag}^{+}$ & $\mathrm{Cd}^{2+}$ \\
\hline $\mathbf{1 7 a}^{\mathrm{a}}$ & 19 & 19 & 39 & 45 & 24 & 15 & 40 & 37 \\
$\mathbf{2 4}^{\mathrm{b}}$ & 2 & 5 & 2 & 4 & 4 & 3 & 13 & 30 \\
\hline
\end{tabular}

aData adapted from reference [67]. b Data adapted from reference [39]. 


\begin{tabular}{llllllllllll}
\multicolumn{2}{l}{ Table 5: Percentage extraction of lanthanide-metal picrates into $\mathrm{CH}_{2} \mathrm{Cl}_{2}$. } & & & & \\
& $\mathrm{La}^{3+}$ & $\mathrm{Ce}^{3+}$ & $\mathrm{Pr}^{3+}$ & $\mathrm{Nd}^{3+}$ & $\mathrm{Sm}^{3+}$ & $\mathrm{Eu}^{3+}$ & $\mathrm{Gd}^{3+}$ & $\mathrm{Dy}^{3+}$ & $\mathrm{Er}^{3+}$ & $\mathrm{Yb}^{3+}$ \\
\hline $\mathbf{1 7 a ^ { \mathrm { a } }}$ & 28 & 34 & 34 & 34 & 31 & 30 & 17 & 18 & 13 & 13 \\
$\mathbf{2 4}^{\mathrm{b}}$ & 6 & 5 & 5 & 6 & 6 & 6 & 6 & 5 & 6 & 7 \\
\hline
\end{tabular}

${ }^{\mathrm{a}}$ Data adapted from reference [70]. ${ }^{\mathrm{b}}$ Data adapted from reference [39].

determined by UV absorption spectrophotometry in methanol at $25{ }^{\circ} \mathrm{C}$, by using chloride salts. The same positive discrimination for the light lanthanides was observed $(\log \beta=5.5$ and 3.4 for $\mathrm{La}^{3+}$ and $\mathrm{Yb}^{3+}$, respectively).

The complexing ability of the ionizable tricarboxylic acid 14a towards lanthanides $\mathrm{Pr}^{3+}, \mathrm{Eu}^{3+}$ and $\mathrm{Yb}^{3+}$ and actinide $\mathrm{Th}^{4+}$ was established in methanol, by potentiometry measurements [71] Results showed that the complex formed with $\mathrm{Th}^{4+}$ was more stable than the complexes of lanthanides ( $\log \beta$ values are 20.5, 19.6, 21.3 and 23.1, respectively).

\section{Other applications}

\subsection{Hosts for fullerenes}

One of the remarkable characteristics of calixarenes is the bowl shape of the molecule. In the case of oxacalix[3]arenes, the bowl is quite shallow, which indicates that they may be good hosts for spherical guests and immediately suggests binding to fullerenes. Furthermore, the macrocyclic bowl is the perfect size for $\mathrm{C}_{60}$ and has a complementary threefold-symmetry element.

Based on the knowledge that $p$-tert-butylcalix[8]arene was able to complex $C_{60}[72,73]$ Shinkai investigated the interaction of $\mathrm{C}_{60}$ with 3a in 1997 by UV-vis spectroscopy [74]. In a later full paper, $\mathrm{UV}$-vis absorption spectra of $\mathrm{C}_{60}$ were recorded with calix $[n]$ arenes and oxacalix[3]arenes. The interaction of fullerenes with calixarenes affected the spectra between 420 and $450 \mathrm{~nm}$ [75]. By using the Benesi-Hildebrand method, 3a was shown to bind to $\mathrm{C}_{60}$ with a $K_{\text {assoc }}$ of $35.5 \mathrm{M}^{-1}$ in toluene at $25^{\circ} \mathrm{C}$; however, when methylated on the lower rim, no binding was observed. Molecular modelling was employed to illustrate how the shallow cavity of $\mathbf{3 a}$ allowed for optimum interactions between the oxacalix[3] arene aromatic rings and $\mathrm{C}_{60}$.

While subtle spectroscopic features and computer models appeared to indicate fullerene binding, structural evidence was to be more compelling. In 1998, Fuji reported the solid-state structure of $\mathbf{3} \mathbf{f}$ with $\mathrm{C}_{60}$ as proof of 1:1 binding [76]. Alignment of the oxacalix[3] arene $C_{3}$ axis with the same symmetry axis of the fullerenes is observed. This arrangement maximizes the number of points of contact within the supramolecular complex, thereby enhancing the van der Waals interactions. In the same paper, the association constants of several oxacalix[3]arenes were calculated by the Rose-Drago method based on absorption features at 425 or $430 \mathrm{~nm}$ in toluene. The strongest binding was observed for $3 \mathbf{a}\left(35.6 \mathrm{M}^{-1}\right)$ and the weakest for 3h $\left(9.1 \mathrm{M}^{-1}\right)$.

Although spectroscopic methods are widely used to determine host-guest association constants, Georghiou has argued persuasively that spectral changes in solution may be due to a combination of several factors, of which host- $\mathrm{C}_{60}$ complex formation is only one [77]. Consequently, reported $K_{\text {assoc }}$ values determined by this method should be treated with some caution.

Fullerene derivatives that lack some of the symmetry of the parent compound have been shown to bind to oxacalix[3]arenes, as in Fuji's X-ray structure of 1,4-bis(9-fluorenyl)-1,4dihydro[60]fullerene with $3 f$ shown in Figure 24, in which the oxacalix[3] arene binds to the $\mathrm{C}_{60}$ derivative with the fluorenyl substituents oriented away from the macrocycle [78].

Raston reported that $p$-benzyloxacalix[3]arene (3i) formed a 2:1 complex with $\mathrm{C}_{60}$ in toluene [79]. The X-ray crystal structure showed how the two oxacalix[3]arenes bound on opposite sides of the fullerene, with their benzyl arms interdigitated. When the complex was isolated and added to $\mathrm{CH}_{2} \mathrm{Cl}_{2}$ then the fullerene was released. The method could be used to separate $\mathrm{C}_{60}$ from fullerite (a mixture of fullerenes of different sizes) in greater than $99.5 \%$ purity. A similar experiment was undertaken by Georghiou with 6a leading to much higher association constants of $296 \mathrm{M}^{-1}$ (toluene) and $441 \mathrm{M}^{-1}$ (benzene) [23]. Crystallography revealed a similar interdigitated 2:1 complex to that observed by Raston for 3i (Figure 25).

One area of interest has been the selective separation of $\mathrm{C}_{70}$ from a mixture of fullerenes. Komatsu proposed a method for the preferential precipitation of $\mathrm{C}_{70}$ over $\mathrm{C}_{60}$ with $p$-halooxacalix[3]arenes [80]. $p$-Iodooxacalix[3] arene (3j) was able to achieve $90 \%$ extraction with a selectivity approaching $90 \%$.

An unexpected effect of fullerene complexation was that a water-soluble capsule formed from two $p$-tert-butyloxacalix[3]arenes with trimethylammonium groups on the lower 


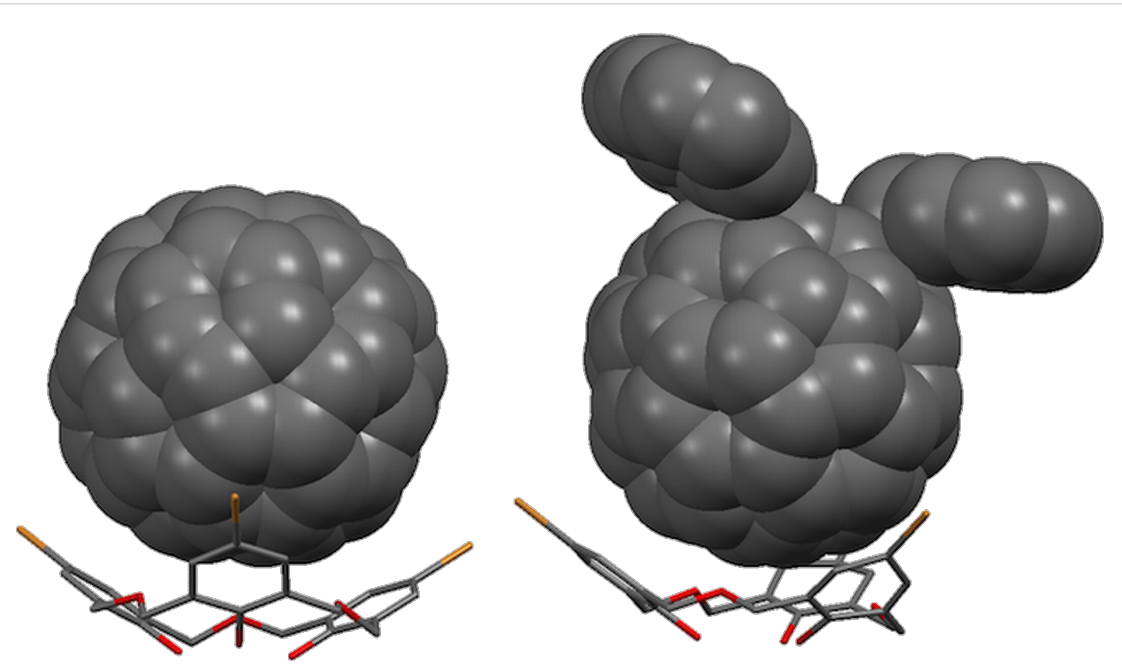

Figure 24: X-ray crystal structures of $3 \mathbf{f}$ with $\mathrm{C}_{60}$ (CCDC ID 182801, left) [76] and a 1,4-bis(9-fluorenyl) $\mathrm{C}_{60}$ derivative (CCDC ID 139793, right) [78].
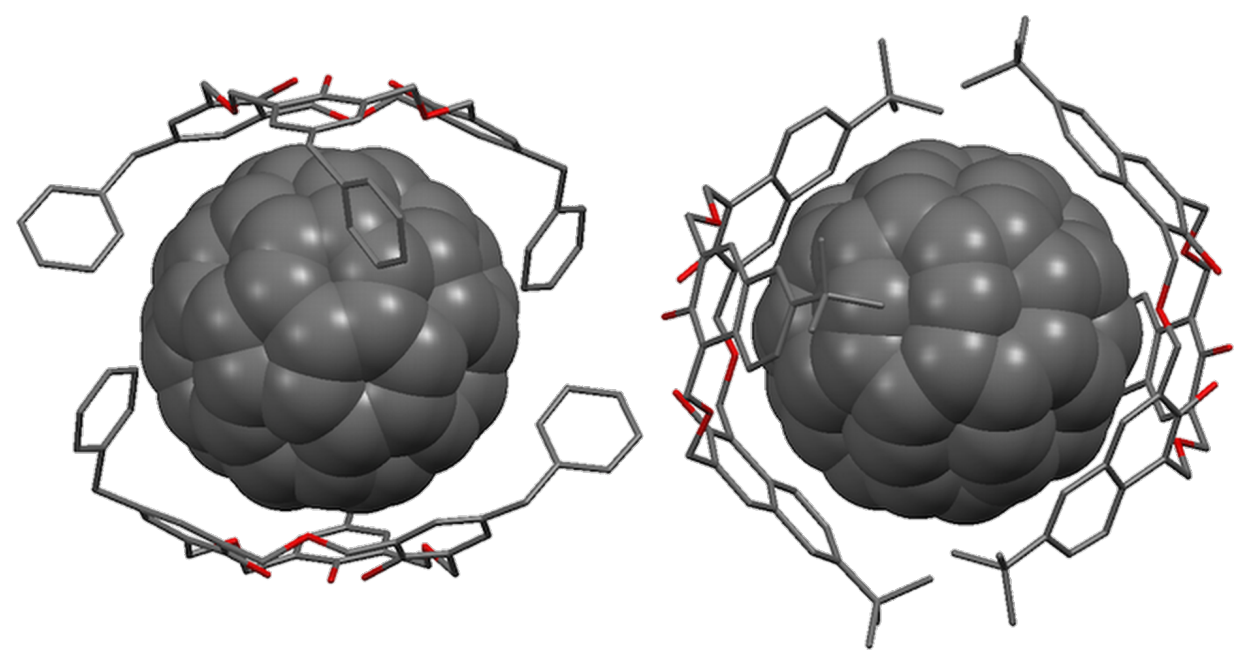

Figure 25: X-Ray crystal structure of $\mathbf{3 i}$ and $6 \mathbf{6}$ encapsulating $\mathrm{C}_{60}$ (CCDC ID 102473 and 166077) [23,79].

rims, 51, which bound $\mathrm{C}_{60}$, was able to cleave DNA (Figure 26) [81]. The capsule was solubilized as the $\mathrm{MsO}^{-}$salt and applied to a supercoiled form of DNA. In the absence of light, no change was seen, but in the presence of visible light the DNA became "nicked", that is, a phosphodiester bond in one strand was broken. The authors speculated that the cationic complex was able to bind to the anionic DNA whereupon ${ }^{1} \mathrm{O}_{2}$ generated by photoinduced electron transfer from guanine and $\mathrm{C}_{60}$, or alternatively photochemically by $\mathrm{C}_{60}$ alone, cleaves the DNA strand. Ikeda later advanced this line of research to carbohydrate-containing oxacalix[3]arenes that functioned in water [82].

The same cationic complex was deposited as a monolayer onto an alkylsulfonate coated gold surface and elicited both a redox response, as determined by cyclic voltammetry, and a photochemical response to visible light $[83,84]$. The optical response was studied further [85], and a transient band was observed at $545 \mathrm{~nm}$, which was not present in the spectrum of $\mathrm{C}_{60}$ alone. The origin of the band was ascribed to $\mathrm{C}_{60}$-capsule triplet-triplet absorption.

As discussed above, oxacalix[3] arenes with pyridine in the para-position and ethyl esters on the lower rim are able to form capsules through coordination to palladium [53]. Capsule 46 was shown to bind to $\mathrm{C}_{60}$ by the presence of two peaks in the ${ }^{13} \mathrm{C}$ NMR spectrum, which did not coalesce even at $90{ }^{\circ} \mathrm{C}$. ${ }^{1} \mathrm{H}$ NMR was used to determine an association constant of $54 \mathrm{M}^{-1}$ in $\mathrm{Cl}_{2} \mathrm{CDCDCl}_{2}$ at $60{ }^{\circ} \mathrm{C}$. An asymmetric capsule incorporating an oxacalix[3] arene and three $\mathrm{Zn}(\mathrm{II})$ porphyrin 


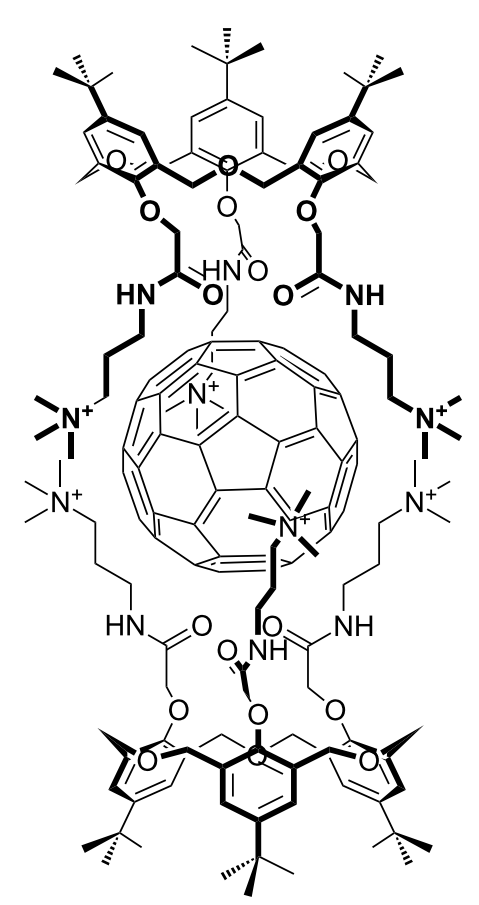

51

Figure 26: $\mathrm{A} \mathrm{C}_{60}$ complexing cationic oxacalix[3]arene 51 [81].

moieties, 52, was also able to bind $\mathrm{C}_{60}$ in a similar fashion with an association constant of $60 \mathrm{M}^{-1}$ in toluene- $d_{8}$ at $-30{ }^{\circ} \mathrm{C}$ [86].

Another strategy to promote fullerene inclusion in an oxacalix[3] arene was to link the two by a triethylene glycol tether to form a molecular cup-and-ball 53 [87]. In addition to self-inclusion, the authors also proposed the formation of higher order oligomers arising from $\mathrm{C}_{60}$ inclusion in a neighbouring oxacalixarene through the change in conformation illustrated in Figure 27.

\subsection{Fluorescent chemosensors}

In order to determine the equilibrium constants with quaternary ammonium ions, Shinkai [88] prepared an oxacalixarene with pendent pyrene groups, 54, which fluoresced at $480 \mathrm{~nm}$. Oxacalix[3] arene fluorescence was significantly quenched in the presence of $n$-hexyl ammonium cations $\left(n-\mathrm{HexNH}_{3}{ }^{+}\right)$, but only in the partial-cone conformation, as the ammonium cation forced the lower-rim pyrene groups apart. The same cation had a much higher affinity for cone-54 through its complementary binding sites, but approached these from the upper rim, leaving the excimer fluorescence unaffected. Yamato also pursued this path, preparing a tris(pyrenyl) derivative $\mathbf{5 5}$ in the cone conformer by employing "click" chemistry (Scheme 21) [89]. One interesting aspect of the synthesis was that the tris(propargyl) click precursor crystallized as a mixture of cone and partial-cone conformers, yet addition of $n$ - $\mathrm{BuNH}_{3}{ }^{+} \mathrm{ClO}_{4}{ }^{-}$ to the conformers in solution pushed the equilibrium towards the cone. Cone-55 gave a response to $\mathrm{Pb}^{2+}$ through the enhancement of minor fluorescence peaks between 370 and $400 \mathrm{~nm}$, which were unaffected by other metal guests. The group also reported that the fluorescence intensity at $396 \mathrm{~nm}$ increased linearly when $\mathrm{Zn}^{2+}$ was added and that the 1:1 complex of this macrocycle gave an increasing linear response at $485 \mathrm{~nm}$ to $\mathrm{H}_{2} \mathrm{PO}_{4}{ }^{-}[90]$.
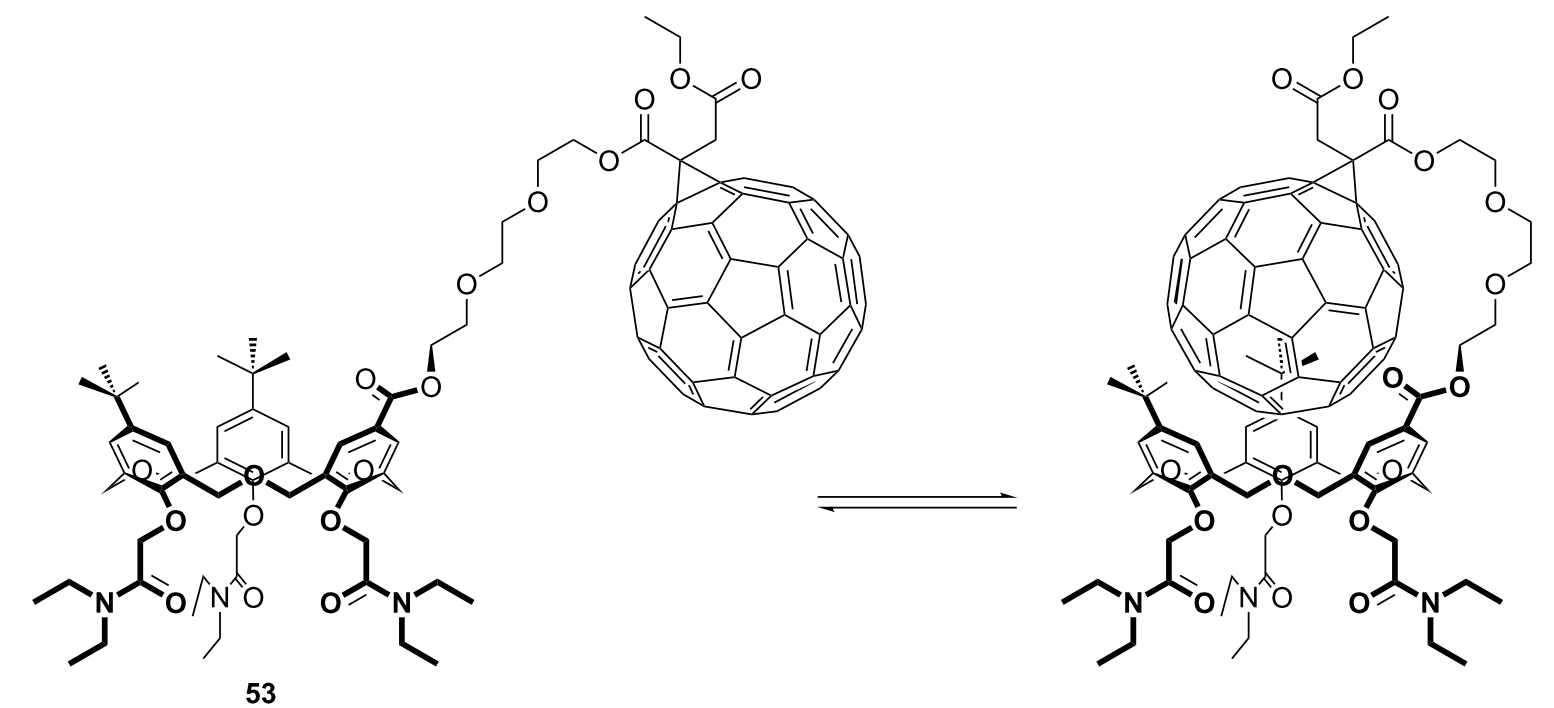

Figure 27: An oxacalix[3]arene- $\mathrm{C}_{60}$ self-associating system 53 [87]. 


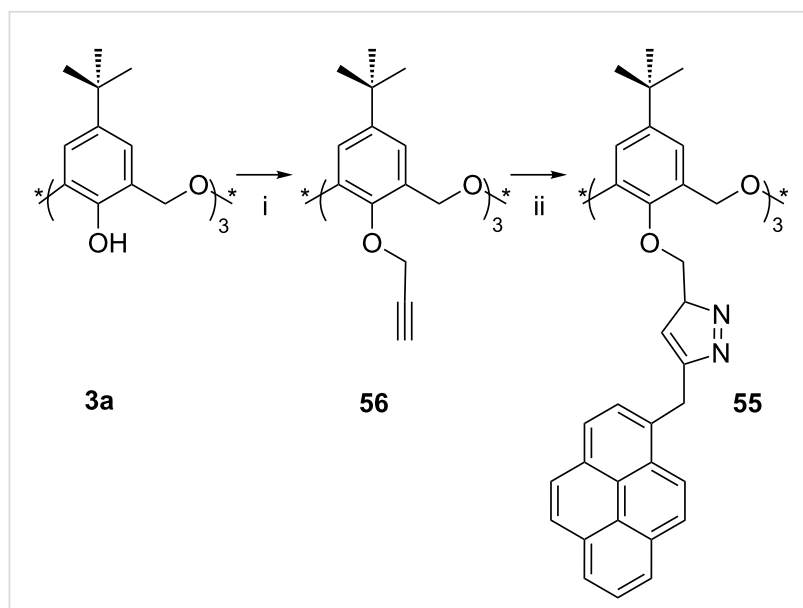

Scheme 21: Synthesis of fluorescent pyrene derivative 55: (i) Propargyl bromide, acetone; (ii) Cul, 1-azidomethylpyrene, $\mathrm{THF} / \mathrm{H}_{2} \mathrm{O}$ [89].

Rhodamine substituents can be introduced to the lower rim of the cone-14a through the ethylamine derivative of the dye (Scheme 22) [91]. Fluorescence enhancement was observed between $500 \mathrm{~nm}$ and $600 \mathrm{~nm}$ upon addition of $\mathrm{Fe}^{3+}, \mathrm{Ni}^{2+}$ and $\mathrm{Sb}^{3+}$ to 57, turning the colourless solution fluorescent orange-yellow, together with a colourless-to-magenta colourimetric response.

Kang found that the reaction of 3a with 1-bromo-4-nitrobenzyl acetate gave the trisubstituted nitrobenzene derivative $\mathbf{5 8}$ in $40 \%$ yield (Scheme 23) as the partial-cone conformer [92]. When a range of fluorescent ammonium cations incorporating pyrene, anthracene or naphthalene groups was tested, quenching was observed. Association constants were determined to be in the range of $1850 \mathrm{M}^{-1}$ to $78000 \mathrm{M}^{-1}$. The uncharged

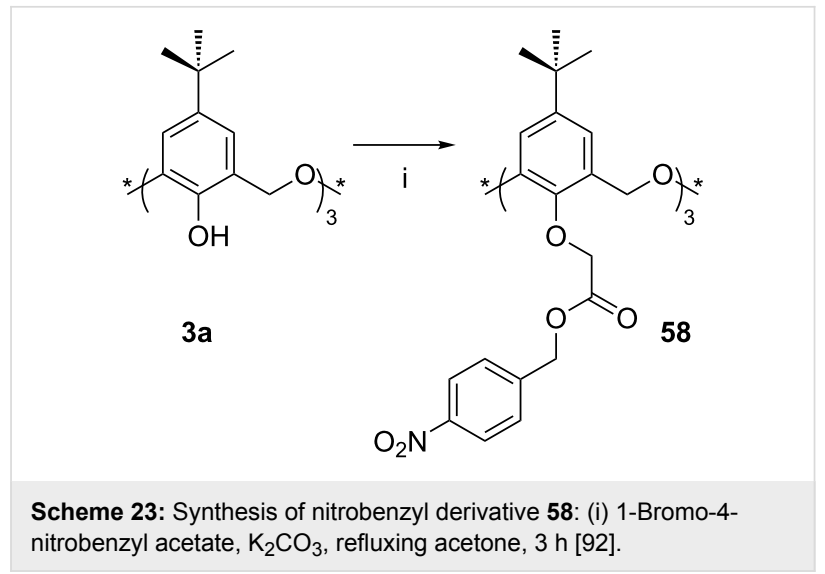

pyrenemethylamine was not bound at all, and a trimethylpyrenium cation was weakly bound $\left(K_{\mathrm{assoc}}=300 \mathrm{M}^{-1}\right)$.

\section{3 lon-selective electrodes}

Given the apparent oxacalix[3] arene selectivity for $\mathrm{Na}^{+}$and certain protonated amines it is likely that they can act as ionselective agents in electrodes. This aspect of oxacalix[3]arene research demonstrates that they are not limited to fluorescent sensor applications but can also function in the electrochemical sphere.

5.3.1 Dopamine recognition: The first example of oxacalixarenes being used as electrode modifiers was in 1999 when Odashima incorporated cone p-tert-butyloxacalix[3]arene tri(nbutyl ether) (10) in a PVC matrix liquid membrane [93]. The electrode displayed excellent selectivity for dopamine over biologically important alkali-metal cations $\mathrm{K}^{+}$, by a factor of 150 , and $\mathrm{Na}^{+}$, by a factor of 1600 . Selectivity for dopamine against other catecholamine neurotransmitters, such as adrenaline and<smiles>Cc1cc(C(C)C)cc(CO[Al])c1OCC(=O)O</smiles>

$14 a$<smiles>NCCN1C(=O)c2ccccc2C12c1ccc(N)cc1Oc1cc(N)ccc12</smiles><smiles>COCc1cc(C(C)(C)C)cc(C(C)(C)C)c1OCC(=O)NCCN1C(=O)c2ccccc2C12c1ccc(N)cc1Oc1cc(N)ccc12</smiles> 
noradrenaline, was also greater by a factor of at least 100 . This selectivity obtained with $\mathbf{1 0}$ is a very promising result with the potential to be developed into a dopamine sensor for use under physiological conditions. The dopamine selectivity of the trimethyl ether analogue 7 was investigated by Arrigan at the interface between water and 1,2-dichloroethane using cyclic voltammetry [94]. The $\log K_{\text {assoc }}$ value obtained was 8.3 , which was significantly higher than those for $\mathrm{Na}^{+}$and $\mathrm{K}^{+}$. The $\log$ $K_{\text {assoc }}$ comparative data for dibenzo-18-crown- 6 were 7.6 for the dopamine complex and 10.1 for the $\mathrm{K}^{+}$complex, indicating that not only was 7 a better host for dopamine but also that $\mathrm{K}^{+}$ would not be bound preferentially as is the case for the crown ether.

5.3.2 Sensing $\mathbf{P b}^{2+}$ : In 2007, Yaftian incorporated Matt's phosphorylated derivative $\mathbf{2 6}$ in a membrane solution, prepared by dissolving $\mathrm{PVC}, \mathrm{NaBF}_{4}$, a plasticizer and the oxacalixarene in THF, which was then used to coat a graphite electrode [95]. This electrode gave a good Nernstian response of $29.7 \mathrm{mV} /$ decade, over a concentration range of $1 \times 10^{-8} \mathrm{M}$ to 1 $\times 10^{-4} \mathrm{M}$ of $\mathrm{Pb}^{2+}$ ions, with a detection limit of $0.4 \times 10^{-8} \mathrm{M}$. When tested in mixtures of several competing cations (such as alkali, alkaline earth, transition, heavy metal, lanthanide and $\mathrm{Th}^{4+}$ ions) the electrode was able to determine the concentration of $\mathrm{Pb}^{2+}$ correctly within $5 \%$, even when other ions were present in tenfold excess.

Diethylacetamide 17a was also used as an active material in ion-selective electrodes to check the detection of different types of cations [96]. Optimization of the PVC membrane composition was achieved by using different plasticizers (DEHA, $o$-NPOE and BBPA). The performance of the ISE incorporating $17 \mathbf{a}$ indicated a high affinity for $\mathrm{Pb}^{2+}$ and the use of DEHA as the best plasticizer.

\subsection{Biological models}

The crystal structure of the complex of $\mathbf{1 7 a}$ with $\mathrm{NaPF}_{6}$ (Figure 28) shows how the lower-rim binding site, composed of phenolic oxygen and amide nitrogen atoms, is predisposed to bind $\mathrm{Na}^{+}$in its ideal octahedral environment [97]. The compound has been proposed to be an artificial analogue for the filter region in cation channels formed by naturally occurring transmembrane proteins and has been shown to have some activity on transmembrane ion transport in cells.

\section{Conclusion}

Since their origins in the phenol-formaldehyde chemistry of the 1960s, oxacalix[3]arenes and their analogues have shown themselves to be interesting and useful additions to the large array of artificial macrocycles that has been developed by supramolecular chemists. The $C_{3}$ symmetry of oxacalix[3]arenes,

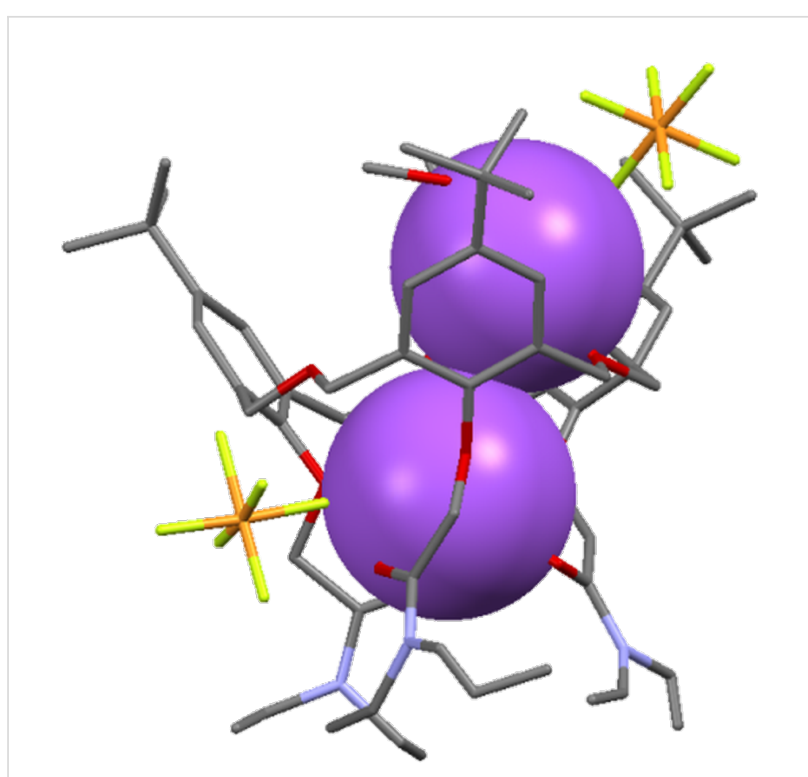

Figure 28: X-ray crystal structure of $\left[\mathrm{Na}_{2} \cdot 17 \mathrm{a}\right]\left(\mathrm{PF}_{6}\right)_{2}(\mathrm{CCDC} I D$ 116656) [97].

commonly encountered in nature but relatively rare in synthetic host molecules, has made them valuable members of the calixarene family, with an affinity for guests with complementary binding requirements. While the parent compounds do not form particularly strong complexes with metal ions, their $O$-alkylated derivatives are easy to prepare and can show very efficient and selective cation binding, extending to alkyl ammonium salts. Advances in upper-rim functionalization allow for the formation of molecular capsules and chiral recognition sites, and applications have been found in fluorescence sensors, ionselective electrodes and the extraction of pure $\mathrm{C}_{60}$ and $\mathrm{C}_{70}$ from crude fullerite. Fifty years on from their discovery by Hultzsch, oxacalix[3]arenes and their derivatives are still able to amaze chemists with their elegant symmetry and fascinating complexes.

\section{Acknowledgements}

The use of the EPSRC's Chemical Database Service at Daresbury is gratefully acknowledged. KC thanks the Rhône-Alpes Regional Council for an Explo'ra Sup scholarship.

\section{References}

1. Gutsche, C. D. Calixarenes: An Introduction; Monographs in Supramolecular Chemistry, 2nd ed.; Royal Society of Chemistry: Cambridge, U.K., 2008.

2. Sliwa, W.; Kozlowski, C. Calixarenes and Resorcinarenes: Synthesis, Properties and Applications; Wiley VCH: Weinheim, Germany, 2009.

3. Böhmer, V. Angew. Chem., Int. Ed. Engl. 1995, 34, 713-745. doi:10.1002/anie.199507131

4. Brodesser, G.; Vögtle, F. J. Incl. Phenom. Mol. Recognit. Chem. 1994, 19, 111-135. doi:10.1007/BF00708978 
5. Gutsche, C. D.; Bauer, L. J. J. Am. Chem. Soc. 1985, 107, 6052-6059. doi:10.1021/ja00307a038

6. Cragg, P. J. Homocalixarenes. In Encyclopedia of Supramolecular Chemistry; Atwood, J. L.; Steel, J. W., Eds.; Marcel Dekker: New York, 2004; pp 649-657.

7. Späth, A.; König, B. Beilstein J. Org. Chem. 2010, 6, No. 32. doi:10.3762/bjoc.6.32

8. Yamato, D. J. J. Inclusion Phenom. Mol. Recognit. Chem. 1998, 32, 195-207. doi:10.1023/A:1008011410507

9. Shokova, E. A.; Kovalev, V. V. Russ. J. Org. Chem. 2004, 40, 607-643. doi:10.1023/B:RUJO.0000043707.97314.52

10. Shokova, E. A.; Kovalev, V. V. Russ. J. Org. Chem. 2004, 40, 1547-1578. doi:10.1007/s11178-005-0062-9

11. Hultzsch, K. Kunststoffe 1962, 52, 19-24.

12. Masci, B.; Finelli, M.; Varrone, M. Chem.-Eur. J. 1998, 4, 2018-2030. doi:10.1002/(SICl)1521-3765(19981002)4:10<2018::AID-CHEM2018> 3.0.CO;2-I

13. Mukoyama, Y.; Tanno, T. Org. Coat. Plast. Chem. 1979, 40, 894-897.

14. Dhawan, D.; Gutsche, C. D. J. Org. Chem. 1983, 48, 1536-1539. doi:10.1021/j000157a033

15. Hampton, P. D.; Bencze, Z.; Tong, W.; Daitch, C. E. J. Org. Chem. 1994, 59, 4838-4843. doi:10.1021/jo00096a026

16. Zerr, P.; Mussrabi, M.; Vicens, J. Tetrahedron Lett. 1991, 32, 1879-1880. doi:10.1016/S0040-4039(00)85986-9

17. Suzuki, K.; Minami, H.; Yamagata, Y.; Fuji, S.; Tomita, K.-I.; Asfari, Z.; Vicens, J. Acta Crystallogr., Sect. C: Cryst. Struct. Commun. 1992, 48, 350-352. doi:10.1107/S0108270191010399

18. Miah, M.; Romanov, N. N.; Cragg, P. J. J. Org. Chem. 2002, 67, 3124-3126. doi:10.1021/jo025597a

19. Tsubaki, K.; Otsubo, T.; Tanaka, K.; Fuji, K.; Kinoshita, T. J. Org. Chem. 1998, 63, 3260-3265. doi:10.1021/jo971945a

20. Ashram, M.; Mizyed, S.; Georghiou, P. E. J. Org. Chem. 2001, 66, 1473-1479. doi:10.1021/jo001518o

21. Tsubaki, K.; Morimoto, T.; Otsubo, T.; Kinoshita, T.; Fuji, K. J. Org. Chem. 2001, 66, 4083-4086. doi:10.1021/jo0100502

22. Komatsu, N. Tetrahedron Lett. 2001, 42, 1733-1736. doi:10.1016/S0040-4039(00)02336-4

23. Mizyed, S.; Ashram, M.; Miller, D. O.; Georghiou, P. E. J. Chem. Soc., Perkin Trans. 2 2001, 1916-1919. doi:10.1039/B105019M

24. Araki, K.; Inada, K.; Otsuka, H.; Shinkai, S. Tetrahedron 1993, 49 , 9465-9478. doi:10.1016/S0040-4020(01)80216-7

25. Matsumoto, H.; Nishio, S.; Takeshita, M.; Shinkai, S. Tetrahedron 1995, 51, 4647-4654. doi:10.1016/0040-4020(95)00165-5

26. Cragg, P. J.; Drew, M. G. B.; Steed, J. W. Supramol. Chem. 1999, 11, 5-15. doi:10.1080/10610279908048711

27. Yamato, T.; Haraguchi, H.; Nishikawa, J.-I.; Ide, S.; Tsuzuki, H. Can. J. Chem. 1998, 76, 989-996. doi:10.1139/v98-102

28. Yamato, T.; Zhang, F.; Sato, T.; Ide, S. J. Chem. Res., Synop. 2000, 10-12. doi:10.3184/030823400103165707

29. Araki, K.; Hashimoto, N.; Otsuka, H.; Shinkai, S. J. Org. Chem. 1993, 58, 5958-5963. doi:10.1021/jo00074a021

30. Ashram, M.; Mizyed, S.; Georghiou, P. E. Org. Biomol. Chem. 2003, 1, 599-603. doi:10.1039/b209046p

31. Takeshita, M.; Inokuchi, F.; Shinkai, S. Tetrahedron Lett. 1995, 36, 3341-3344. doi:10.1016/0040-4039(95)00536-L

32. Khrifi, S.; Guelzim, A.; Baert, F.; Mussrabi, M.; Asfari, Z.; Vicens, J. Acta Crystallogr., Sect. C: Cryst. Struct. Commun. 1995, 51, 153-157. doi:10.1107/S0108270194008036
33. Yamato, T.; Zhang, F.; Tsuzuki, H.; Miura, Y. Eur. J. Org. Chem. 2001, 1069-1075.

doi:10.1002/1099-0690(200103)2001:6<1069::AID-EJOC1069>3.0.CO ;2-R

34. Yamato, T.; Zhang, F. L. J. Inclusion Phenom. Macrocyclic Chem. 2001, 39, 55-64. doi:10.1023/A:1008196612553

35. Takimoto, M.; Ni, X.-L.; Rahman, S.; Xi, Z.; Yamato, T. J. Inclusion Phenom. Macrocyclic Chem. 2011, 70, 69-80. doi:10.1007/s10847-010-9863-8

36. Ni, X.-L.; Rahman, S.; Zeng, X.; Hughes, D. L.; Redshaw, C.; Yamato, T. Org. Biomol. Chem. 2011, 9, 6535-6541. doi:10.1039/c1ob05564j

37. Yamato, T.; Rahman, S.; Zeng, X.; Kitajima, F.; Gil, J. T. Can. J. Chem. 2006, 84, 58-64. doi:10.1139/v05-260

38. Ohkanda, J.; Shibui, H. Chem. Commun. 1998, 375-376. doi:10.1039/a706869g

39. Marcos, P. M.; Ascenso, J. R.; Segurado, M. A. P.; Bernardino, R. J.; Cragg, P. J. Tetrahedron 2009, 65, 496-503. doi:10.1016/j.tet.2008.11.005

40. Dieleman, C. B.; Matt, D.; Neda, I.; Schmutzler, R.; Harriman, A.; Yaftian, R. Chem. Commun. 1999, 1911-1912. doi:10.1039/a905677g

41. Hampton, P. D.; Daitch, C. E.; Duesler, E. N. New J. Chem. 1996, 20 , 427-432.

42. Casnati, A.; Pochini, A.; Ungaro, R.; Ugozzoli, F.; Arnaud, F.; Fanni, S.; Schwing, M.-J.; Egberink, R. J. M.; de Jong, F.; Reinhoudt, D. N. J. Am. Chem. Soc. 1995, 117, 2767-2777. doi:10.1021/ja00115a012

43. Liu, S.-L.; Gong, S.-L.; Chen, Y.-Y. Chin. J. Chem. 2005, 23, 1651-1654. doi:10.1002/cjoc.200591651

44. Liu, S.-L.; Gong, S.-L.; Zheng, Q.; Chen, Y.-Y.; Wu, X.-J. J. Chem. Res., Synop. 2005, 126-129. doi: $10.3184 / 0308234054497218$

45. Tsubaki, K.; Otsubo, T.; Kinoshita, T.; Kawada, M.; Fuji, K. Chem. Pharm. Bull. 2001, 49, 507-509. doi:10.1248/cpb.49.507

46. Tsubaki, K.; Otsubo, T.; Morimoto, T.; Maruoka, H.; Furukawa, M.; Momose, Y.; Shang, M.; Fuji, K. J. Org. Chem. 2002, 67, 8151-8156. doi:10.1021/jo026152p

47. Zhong, Z.; Ikeda, A.; Shinkai, S. J. Am. Chem. Soc. 1999, 121, 11906-11907. doi:10.1021/ja9925002

48. Miah, M.; Pavey, K. D.; Gun'ko, V. M.; Sheehan, R.; Cragg, P. J. Supramol. Chem. 2004, 16, 185-192. doi:10.1080/10610270310001644473

49. Hinrichs, M.; Hofbauer, F. R.; Klüfers, P.; Suhanji, M. Inorg. Chem. 2006, 45, 6688-6693. doi:10.1021/ic0603048

50. Kawaguchi, M.; Ikeda, A.; Shinkai, S. Tetrahedron Lett. 2001, 42, 3725-3728. doi:10.1016/S0040-4039(01)00463-4

51. Araki, K.; Hayashida, H. Tetrahedron Lett. 2000, 41, 1807-1810. doi:10.1016/S0040-4039(00)00034-4

52. Ikeda, A.; Yoshimura, M.; Tani, F.; Naruta, Y.; Shinkai, S. Chem. Lett. 1998, 27, 587-588. doi:10.1246/cl.1998.587

53. Ikeda, A.; Udzu, H.; Zhong, Z.; Shinkai, S.; Sakamoto, S.; Yamaguchi, K. J. Am. Chem. Soc. 2001, 123, 3872-3877. doi:10.1021/ja003269r

54. Masci, B. Tetrahedron 1995, 51, 5459-5464. doi:10.1016/0040-4020(95)00207-O

55. Hampton, P. D.; Daitch, C. E.; Alam, T. M.; Bencze, Z.; Rosay, M. Inorg. Chem. 1994, 33, 4750-4758. doi:10.1021/ic00099a028

56. Hampton, P. D.; Daitch, C. E.; Alam, T. M.; Pruss, E. A. Inorg. Chem. 1997, 36, 2879-2883. doi:10.1021/ic9611195 
57. Redshaw, C.; Rowan, M. A.; Warford, L.; Homden, D. M.; Arbaoui, A.; Elsegood, M. R. J.; Dale, S. D.; Yamato, T.; Peréz Casas, C.; Matsui, S.; Matsuura, S. Chem.-Eur. J. 2007, 13, 1090-1107. doi:10.1002/chem.200600679

58. Notestein, J. M.; Andrini, L. R.; Kalchenko, V. I.; Requejo, F. G.; Katz, A.; Iglesia, E. J. Am. Chem. Soc. 2007, 129, 1122-1131. doi:10.1021/ja065830c

59. Hampton, P. D.; Daitch, C. E.; Duesler, E. N. Inorg. Chem. 1995, 34, 5641-5645. doi:10.1021/ic00126a038

60. Daitch, C. E.; Hampton, P. D.; Duesler, E. N.; Alam, T. M. J. Am. Chem. Soc. 1996, 118, 7769-7773. doi:10.1021/ja9605984

61. Hampton, P. D.; Daitch, C. E.; Shachter, A. M. Inorg. Chem. 1997, 36, 2956-2959. doi:10.1021/ic961445k

62. Thuéry, P.; Nierlich, M.; Masci, B.; Asfari, Z.; Vicens, J. J. Chem. Soc., Dalton Trans. 1999, 3151-3152.

63. Masci, B.; Nierlich, M.; Thuéry, P. New J. Chem. 2002, 26, 120-128. doi:10.1039/b108947c

64. Masci, B.; Nierlich, M.; Thuéry, P. New J. Chem. 2002, 26, 766-774. doi:10.1039/b200734g

65. Araki, K.; Inada, K.; Shinkai, S. Angew. Chem., Int. Ed. Engl. 1996, 35 , 72-74. doi:10.1002/anie.199600721

66. Tsubaki, K.; Morimoto, T.; Otsubo, T.; Fuji, K. Org. Lett. 2002, 4, 2301-2304. doi:10.1021/ol026019j

67. Marcos, P. M.; Ascenso, J. R.; Cragg, P. J. Supramol. Chem. 2007, 19, 199-206. doi:10.1080/10610270601026594

68. Marcos, P. M. et al., manuscript in preparation.

69. Cragg, P. J.; Miah, M.; Steed, J. W. Supramol. Chem. 2002, 14, 75-78. doi:10.1080/10610270290006592

70. Marcos, P. M.; Ascenso, J. R.; Segurado, M. A. P.; Cragg, P. J.; Michel, S.; Hubscher-Bruder, V.; Arnaud-Neu, F. Supramol. Chem. 2011, 23, 93-101. doi:10.1080/10610278.2010.510562

71. Arnaud-Neu, F.; Cremin, S.; Harris, S.; McKervey, M. A.; Schwing-Weill, M.-J.; Schwinté, P.; Walker, A. J. Chem. Soc., Dalton Trans. 1997, 329-334. doi:10.1039/A602631A

72. Atwood, J. L.; Koutsantonis, G. A.; Raston, C. L. Nature 1994, 368, 229-231. doi:10.1038/368229a0

73. Suzuki, T.; Nakashima, K.; Shinkai, S. Chem. Lett. 1994, 23, 699-702. doi:10.1246/cl.1994.699

74. Ikeda, A.; Yoshimura, M.; Shinkai, S. Tetrahedron Lett. 1997, 38, 2107-2110. doi:10.1016/S0040-4039(97)00318-3

75. Ikeda, A.; Suzuki, Y.; Yoshimura, M.; Shinkai, S. Tetrahedron 1998, 54, 2497-2508. doi:10.1016/S0040-4020(98)00012-X

76. Tsubaki, K.; Tanaka, K.; Kinoshita, T.; Fuji, K. Chem. Commun. 1998, 895-896. doi:10.1039/a800078f

77. Georghiou, P. E.; Tran, A. H.; Stroud, S. S.; Thompson, D. W. Tetrahedron 2006, 62, 2036-2044. doi:10.1016/j.tet.2005.09.151

78. Tsubaki, K.; Murata, Y.; Komatsu, K.; Kinoshita, T.; Fuji, K. Heterocycles 1999, 51, 2553-2556. doi:10.3987/COM-99-8650

79. Atwood, J. L.; Barbour, L. J.; Nichols, P. J.; Raston, C. L.; Sandoval, C. A. Chem.-Eur. J. 1999, 5, 990-996. doi:10.1002/(SICI)1521-3765(19990301)5:3<990::AID-CHEM990>3.0. $\mathrm{CO} ; 2-4$

80. Komatsu, N. Org. Biomol. Chem. 2003, 1, 204-209. doi:10.1039/b208107e

81. Ikeda, A.; Hanato, T.; Kawaguchi, M.; Suenaga, H.; Shinkai, S. Chem. Commun. 1999, 1403-1404. doi:10.1039/a903872h

82. Ikeda, A.; Ejima, A.; Nishiguchi, K.; Kikuchi, J.-i.; Matsumoto, T.; Hatano, T.; Shinkai, S.; Goto, M. Chem. Lett. 2005, 34, 308-309. doi: $10.1246 / \mathrm{cl} .2005 .308$
83. Hatano, T.; Ikeda, A.; Akiyama, T.; Yamada, S.; Sano, M.; Kanekiyo, Y.; Shinkai, S. J. Chem. Soc., Perkin Trans. 2 2000, 909-912. doi:10.1039/b000022l

84. Ikeda, A.; Hanato, T.; Shinkai, S.; Akiyama, T.; Yamada, S. J. Am. Chem. Soc. 2001, 123, 4855-4856. doi:10.1021/ja015596k

85. Islam, S. D.-M.; Fujitsuka, M.; Ito, O.; Ikeda, A.; Hanato, T.; Shinkai, S. Chem. Lett. 2000, 29, 78-79. doi:10.1246/cl.2000.78

86. Ikeda, A.; Sonoda, K.; Shinkai, S. Chem. Lett. 2000, 29, 1220-1221. doi:10.1246/cl.2000.1220

87. Ikeda, A.; Nobukuni, S.; Udzu, H.; Zhong, Z.; Shinkai, S. Eur. J. Org. Chem. 2000, 3287-3293. doi:10.1002/1099-0690(200010)2000:19<3287::AID-EJOC3287>3.0.C O;2-R

88. Takeshita, M.; Shinkai, S. Chem. Lett. 1994, 23, 125-128. doi:10.1246/cl.1994.125

89. Ni, X.-L.; Wang, S.; Zeng, X.; Tao, Z.; Yamato, T. Org. Lett. 2011, 13, 552-555. doi:10.1021/ol102914t

90. Ni, X.-L.; Zeng, X.; Redshaw, C.; Yamato, T. J. Org. Chem. 2011, 76, 5696-5702. doi:10.1021/jo2007303

91. Wu, C.; Zhang, W.-J.; Zeng, X.; Mu, L.; Xue, S.-F.; Tao, Z.; Yamato, T. J. Inclusion Phenom. Macrocyclic Chem. 2010, 66, 125-131. doi:10.1007/s10847-009-9665-Z

92. Kang, J.-M.; Cheong, N.-Y. Bull. Korean Chem. Soc. 2002, 23, 995-997. doi:10.5012/bkcs.2002.23.7.995

93. Odashima, K.; Yagi, K.; Tohda, K.; Umezawa, Y. Bioorg. Med. Chem. Lett. 1999, 9, 2375-2378. doi:10.1016/S0960-894X(99)00395-9

94. Herzog, G.; McMahon, B.; Lefoix, M.; Mullins, N. D.; Collins, C. J.; Moynihan, H. A.; Arrigan, D. W. M. J. Electroanal. Chem. 2008, 622, 109-114. doi:10.1016/j.jelechem.2008.05.006

95. Yaftian, M. R.; Parinejad, M.; Matt, D. J. Chin. Chem. Soc. 2007, 54, 1535-1542.

96. Bocheńska, M.; Cragg, P. J.; Guziński, M.; Jasiński, A.; Kulesza, J.; Marcos, P. M.; Pomećko, R. Supramol. Chem. 2009, 21, 732-737. doi:10.1080/10610270902853043

97. Cragg, P. J.; Allen, M. C.; Steed, J. W. Chem. Commun. 1999, 553-554. doi:10.1039/a808492k

\section{License and Terms}

This is an Open Access article under the terms of the Creative Commons Attribution License (http://creativecommons.org/licenses/by/2.0), which permits unrestricted use, distribution, and reproduction in any medium, provided the original work is properly cited.

The license is subject to the Beilstein Journal of Organic Chemistry terms and conditions: (http://www.beilstein-journals.org/bjoc)

The definitive version of this article is the electronic one which can be found at: doi: $10.3762 /$ bjoc. 8.22 